NBER WORKING PAPER SERIES

\title{
QUANTILE TREATMENT EFFECTS OF COLLEGE QUALITY ON EARNINGS: EVIDENCE FROM ADMINISTRATIVE DATA IN TEXAS
}

\author{
Rodney J. Andrews \\ Jing Li \\ Michael F. Lovenheim \\ Working Paper 18068 \\ http://www.nber.org/papers/w18068
}

\author{
NATIONAL BUREAU OF ECONOMIC RESEARCH \\ 1050 Massachusetts Avenue \\ Cambridge, MA 02138 \\ May 2012
}

We would like to thank John DiNardo, Nicole Fortin, Doug Almond, Mark Hoekstra, Jeff Smith, Trevon Logan, and Lock Reynolds as well as seminar participants at the Institute for Research on Poverty Summer Workshop, the NBER Summer Institute Education Workshop, the University of Rochester, the IFS-STICERD Public Economics Seminar, the University of British Columbia, Ohio State University, Emory University and the University of Texas at Arlington, the University of Texas at Dallas for helpful comments and suggestions. We thank Priyanka Singh for excellent research assistance. Rodney Andrews gratefully acknowledges the support of grants from both the Bill and Melinda Gates Foundation and the Smith Richardson Foundation. This research was made possible through data provided by the University of Texas at Dallas Education Research Center. The conclusions of this research do not necessarily reflect the opinions or official position of the Texas Education Agency, the Texas Higher Education Coordinating Board, or the State of Texas. The views expressed herein are those of the authors and do not necessarily reflect the views of the National Bureau of Economic Research.

NBER working papers are circulated for discussion and comment purposes. They have not been peerreviewed or been subject to the review by the NBER Board of Directors that accompanies official NBER publications.

(C) 2012 by Rodney J. Andrews, Jing Li, and Michael F. Lovenheim. All rights reserved. Short sections of text, not to exceed two paragraphs, may be quoted without explicit permission provided that full credit, including $\odot$ notice, is given to the source. 
Quantile Treatment Effects of College Quality on Earnings: Evidence from Administrative

Data in Texas

Rodney J. Andrews, Jing Li, and Michael F. Lovenheim

NBER Working Paper No. 18068

May 2012

JEL No. I21,J24

\begin{abstract}
This paper uses administrative data on schooling and earnings from Texas to estimate the effect of college quality on the distribution of earnings. We proxy college quality using the college sector from which students graduate and focus on identifying how graduating from UT-Austin, Texas AI\&M or a community college affects the distribution of earnings relative to graduating from a non-flagship university in Texas. Our methodological approach uses the rich set of observable student academic ability and background characteristics in the data to adjust the earnings distributions across college sectors for the fact that college sector quality is correlated with factors that also affect earnings. Although our mean earnings estimates are similar to previous work in this area, we find evidence of substantial heterogeneity in the returns to college quality. At UT-Austin, the returns increase across the earnings distribution, while at Texas Al\&M they tend to decline with one's place in the distribution. For community college graduates, the returns relative to non-flagship four-year graduates are negative across most of the distribution of earnings, but they approach zero and become positive for higher earners. Our data also allow us to estimate effects separately by race and ethnicity, and we find that historically under-represented minorities experience the highest returns in the upper tails of the earnings distribution, particularly among UT-Austin and community college graduates. While we focus on graduates, we also show our estimates are robust to examining college attendees as well as to many other changes in the sample and to the estimation strategy. Overall, these estimates provide the first direct evidence of the extent of heterogeneity in the effect of college quality on subsequent earnings, and our estimates point to the need to consider such heterogeneity in human capital models that incorporate college quality.
\end{abstract}

Rodney J. Andrews

7 KHUniversity of Texas at Dallas

800 West Campbell Road

MS WT21

Richardson, TX 75080

and NBER

rodney.j.andrews@utdallas.edu
Michael F. Lovenheim

Department of Policy Analysis and Management

Cornell University

135 Martha Van Rensselaer Hall

Ithaca, NY 14853

and NBER

mfl55@cornell.edu

Jing Li

The University of Tulsa

800 South Tucker Drive

Chapman Hall Room 235

Tulsa, OK 74104

jing-li@utulsa.edu 


\section{Introduction}

A growing body of work in economics seeks to identify the effect of college quality on future labor market outcomes. This literature is motivated by the large amount of heterogeneity in college quality in the United States, both across the two-year, four-year and public, private sectors, but also within each of these sectors. While the average return to college is high and growing (Autor, Katz and Kearney, 2008), these returns may be going largely to those students who attend a high-quality, elite postsecondary school. Because the opportunity cost of attendance, in terms of tuition, fees, and forgone wages, are large, understanding how the choices of college students along dimensions of postsecondary quality affect future earnings is of primary importance.

The previous literature on the returns to college quality have found evidence that students who attend or graduate from higher quality schools earn more in the labor market. ${ }^{1}$ Black and Smith $(2004,2006)$ use matching estimators on National Longitudinal Survey of Youth data to show that students who attend schools with higher observed quality subsequently earn more. Hoekstra (2009) exploits an admissions rule based on GPA and SAT scores at a large flagship state university. Using a regression discontinuity approach, he demonstrates that students attending a state flagship earn $24 \%$ more than those who do not. Due to data limitations, however, he cannot specify a clear counterfactual because he does not observe enrollment among those not admitted to the flagship institution. Using longitudinal data from three surveys conducted by the National Center for Education Statistics, Brewer, Eide and Ehrenberg (1999) employ a selection on observables model and find that students who attend an elite public or private school earn 26-39\% more than those who attend a bottom-ranked public school.

Somewhat in contrast, Dale and Krueger (2002, 2011) employ a matching estimator that compares earnings among students who got into or applied to the same set of schools but who attended schools of different quality. While they find little evidence of an average effect of college quality on earnings when quality is proxied by average SAT scores, they do find evidence that students attending higher tuition schools earn more subsequently. Furthermore,

\footnotetext{
${ }^{1}$ See Hoxby (2009) for a review of this literature.
} 
lower-income and minority students experience higher average returns to quality. This result is suggestive that the average effects estimated in previous work may not accurately characterize the effect of college quality on earnings for many students.

In this paper, we add to the previous literature by estimating how earnings premia of college quality vary across the income distribution using unconditional quantile treatment effect methods. This paper is the first to identify the distribution, rather than the mean, of college quality premia, which is important for several reasons. First, examining average returns to quality may miss substantial heterogeneity across students in the effect of college quality on earnings. College tuition could exacerbate these differences, as tuition and fees at higher-quality schools typically are higher than at low-quality schools. ${ }^{2}$ If earnings premia from college quality only flow to certain students, some students may actually be hurt by enrolling in a high-quality university. Second, with large public subsidies for higher education, it is important to understand how higher education choice affects the earnings distribution, not just average earnings. If returns are heterogeneous, the desirability of public support for higher education may rest on what types of students experience the largest returns and on what part of the earnings distribution is shifted due to graduating from a more elite university. Third, identifying the distribution of the effect of college quality on earnings may suggest inefficiencies in the process by which students are matched to postsecondary schools. Understanding the nature of any mismatch is a first step to identifying policies that can help induce students to make optimal attendance decisions.

Previous work on the returns to college quality has focused solely on estimating average (or local average) effects due primarily to data limitations: surveys that contain sufficient background information to control for selection of students into schools typically are too small to be used to identify distributional impacts. In this paper, we use administrative data on all male high school and public college graduates in Texas between 1996 and 2002 that are linked to earnings data from unemployment insurance (UI) records in that state. While we focus on graduates due to the fact that graduation is the salient feature of the postsecondary system observed by employers, we also perform our analysis for college attendees and find similar results

\footnotetext{
${ }^{2}$ For low-income students, this relationship may not hold as many high-quality schools give very generous financial aid packages to lower-income students.
} 
that lead to very similar conclusions. Overall, we observe 94,071 male graduates in our sample. Because these men all attended high school in Texas, we are able to link them to their high school records, which include standardized test scores, information about their academic track, as well as the high school from which they graduated. This data set is unique in the size of the sample and the richness of the background characteristics we observe about each individual.

Our methodological approach follows the unconditional quantile treatment effects (QTE) methods outlined in DiNardo, Fortin and Lemieux (1996) and Firpo (2007). DiNardo, Fortin and Lemieux (1996) show that, if one has a set of observable characteristics with which to plausibly control for selection, one can construct counterfactual outcome distributions by reweighting the control group earnings distribution by the log odds ratio of treatment generated from a regression of the probability of treatment on the observables. As described in Firpo (2007), the quantile treatment effects $^{3}$ can be estimated by taking the difference between the actual treated distribution and the counterfactual untreated distribution at a given quantile. Identification of the QTE also requires a "rank permanence" assumption, which we argue is plausible in the given context. Even without the rank permanence assumption, however, we still are able to identify the effect of college quality on the distribution of earnings, which is of high importance for policy purposes in its own right.

We proxy for college quality by partitioning the Texas higher education system into four groups: University of Texas at Austin (UT-Austin), Texas A\&M University at College Station (TAMU), all other four-year public universities, and all public two year colleges. The first two groups represent the two flagship schools in the state of Texas, and we split them up because UT-Austin is typically higher-ranked and because TAMU is highly focused on engineering and agriculture. Examining these schools separately allows us to measure more precisely the educational environments faced by students in the highest quality public schools in Texas. Fouryear public universities outside of UT-Austin and TAMU represent our control group, and we also examine how community college graduates' earnings compare to this control group.

Our estimates point to large amounts of heterogeneity in the returns to college quality. While our mean estimates are similar to those from previous work, the quantile treatment effects are

\footnotetext{
${ }^{3}$ Firpo (2007) distinguishes between the "quantile treatment effect," which is the quantile analog to the average treatment effect and the "quantile treatment on the treated" that is the quantile analog to the average treatment effect on the treated. We will use the term quantile treatment effect to refer to the quantile treatment effect on the treated, as that is the parameter we are able to identify.
} 
suggestive that the means do not accurately characterize the returns for most students. For UTAustin graduates, the earnings premiums are mostly increasing across the earnings distribution, from a low of $2.7 \%$ at the $9^{\text {th }}$ percentile to a high of $31.7 \%$ at the $97^{\text {th }}$ percentile. Among Texas A\&M graduates, there is less heterogeneity in returns. However, for these graduates the returns decline across the earnings distribution, from a peak of $36.4 \%$ at the $1^{\text {st }}$ percentile to $17.6 \%$ at the $84^{\text {th }}$ percentile. We present evidence that differences in college majors between UT and TAMU graduates is a plausible explanation for the differences in returns experienced by these students. For community college graduates, the returns are mostly negative and tend to increase with one's place in the earning's distribution. Notably, for about $15 \%$ of the distribution, the estimated returns to community college versus non-flagship four-year graduation are close to zero in magnitude and are not statistically different from zero at the $5 \%$ level. Furthermore, the estimated returns to community college graduation are under $5 \%$ in absolute value for the upper third of the earnings distribution. Given the large cost differences between two-year and four-year schools, these results suggest that community colleges may be optimal for a significant subset of students who are relatively high potential earners and who are choosing between a less-selective four-year school and a community college.

We also examine the distribution of college quality returns separately by race and ethnicity. This is among the first evidence on the returns to college quality by race, because most data sets used in previous work lack minority samples of sufficient size to estimate such parameters with any precision. ${ }^{4}$ At Texas A\&M and at UT-Austin, the heterogeneity in returns across the earnings distribution is much larger for whites than for black, Hispanic or Asian students. The returns are low for black and Hispanic students at UT-Austin across the majority of the distribution but are universally large for these Texas A\&M graduates. At community colleges, we document a substantial earnings penalty for Asian graduates, while for black and Hispanic students the returns are positive and sizable at the top of the earnings distribution. These estimates indicate that for historically under-represented minority groups, the higher earners at community colleges earn substantially more than their counterparts who graduated from a non-flagship public university. For these groups, the average earnings estimates do a poor job

\footnotetext{
${ }^{4}$ The only other paper of which we are aware that examines returns to college quality by race and ethnicity is Dale and Krueger (2011). They estimate average returns, rather than the distribution of returns, for these groups. They find that African American and Hispanic students experience higher returns to college quality than other students on average.
} 
of describing the returns faced by a large proportion of students. Using the average treatment effect on the treated estimates for policy purposes, for example to justify inducing students to attend (non-flagship) four-year rather than two-year schools, may lead to reductions in earnings for many of these students.

Our estimates show substantial heterogeneity in the returns to graduating from postsecondary institutions of different quality, both overall and by racial/ethnic groups. These results are suggestive that mean impacts do not accurately characterize the returns a given student can expect to face when making decisions over colleges of differing quality and point to the need to understand how the variance of expected returns, rather than just the mean, affect student postsecondary attendance decisions across the quality spectrum.

\section{Data}

The data used in this study are derived from three sources: administrative data from the Texas Education Agency (TEA), administrative data from the Texas Higher Education Coordinating Board (THECB), and quarterly earnings data from the Texas Workforce Commission (TWC). The data are housed at the Texas Schools Project, a University of Texas at Dallas Education Research Center (ERC). The data from the TEA and THECB allow a researcher to potentially follow a Texas student from Pre-Kindergarten through college. The data from the TWC are unemployment insurance records and provide information on earnings for Texas residents who work. We use a unique identifier based on an individual's social security number to link the data from these three sources.

Because college quality is difficult to measure with a single variable or set of variables (Black and Smith, 2006), we follow much of the previous literature in proxying college quality by college sector (Brewer, Eide and Ehrenberg, 1999; Hoekstra, 2009; Bound, Lovenheim and Turner, 2010; Bound, Lovenheim and Turner, forthcoming; Lovenheim and Reynolds, 2011). Due to data availability constraints, we focus only on public university graduates, and we split them into four comprehensive and mutually exclusive sectors: UT-Austin, Texas A\&M at College Station, ${ }^{5}$ other four-year public universities (i.e., non-flagship public universities)

\footnotetext{
${ }^{5}$ Hereafter, we will refer to Texas A\&M at College Station only as "Texas A\&M" or "TAMU." This university is to be distinguished from the other Texas A\&M campuses, which are part of the the other four-year sector.
} 
and community colleges. We examine UT-Austin and Texas A\&M separately because they are the flagship universities of the State of Texas. Table 1 shows the observable characteristics of the universities across these sectors. Both UT-Austin and Texas A\&M have higher resources and quality measures than the other four-year and community college sectors. They both have much higher SAT scores and faculty-student ratios as well as spending per student that is twice the amount spent in the non-flagship universities. The two flagship universities also graduate over twice the proportion of students as the other four-year colleges. However, in-state tuition (unadjusted for financial aid) is about $\$ 1,000$ more per year to attend the flagship schools. Community colleges are cheaper to attend than four-year schools as well, but they have far fewer resources than the public four-year sector. Thus, our four sectors have large differences in resources and measurable college quality associated with them, and they also define the relevant college choices for most students in Texas due to the dominance of public universities in that state. $^{6}$

We focus on male graduates from Texas' public colleges and universities who graduated from high school during the years 1996-2002. The total sample size includes 94,071 male graduates, with 9,837 graduates from the University of Texas at Austin, 13,436 graduates from Texas A\&M University-College Station, 47,935 graduates from Texas's other four-year public colleges and universities, and 22,863 graduates from Texas's community colleges. We only include males in the analysis because of the concern that many female college graduates are endogenously missing from the sample due to fertility decisions. The sample includes males who meet the following restrictions: 1) No missing data for any of the covariates, 2) The student must graduate before the age of 25,3$)$ The graduate's earnings for a given year are included only if he worked for four consecutive quarters in the year, with the exception of 2009 where the requirement for inclusion is three consecutive quarters as we only have three quarters of available earnings data for 2009, and 4) The student must not be currently enrolled in graduate school when the earnings are measured. ${ }^{7}$ These restrictions are meant to isolate the earnings of full-time working males, and

\footnotetext{
${ }^{6}$ Unfortunately, we do not have information about students who graduate from private universities. However, public postsecondary schools dominate the higher education market in Texas. In the National Longitudinal Study of 1988, only 9.6\% of Texas high school graduates who went to college attended a private college. In the National Longitudinal Survey of Youth 1997, 11.5\% of students attended a private college. Thus, our focus on public schools, while necessitated by the data, is appropriate given the small proportion of students who enroll in private universities in Texas.

${ }^{7}$ Students who earn a graduate degree are included. The fourth restriction ignores earnings while students are enrolled in graduate school because they likely are not reflective of the student's permanent earnings.
} 
they are similar to the sample restrictions imposed by Hoekstra (2009).

We obtained records of each individual's quarterly earnings from the TWC and examine earnings data for the years 2007-2009. Because these students graduated from high school between 1996 and 2002, they will be between 23 and 31 post-graduation when we observe their earnings. Examining earnings of graduates in their early 20s may be problematic if college quality increases the returns to experience. In such a circumstance, we will understate the earnings of college graduates from higher-quality schools relative to lower-quality schools. However, in Section 4.4 we estimate effects for the older sample who graduated from high school in 1996-1998. The results using this sample are similar to the estimates for the sample as a whole, which is suggestive that the relative inexperience of our sample is not driving our results. The use of data from 2007-2009 also is potentially problematic because of the large increase in unemployment rates during this period in the U.S.. Since our data only include full-time workers, the recession may cause us to miss many workers, and in particular may cause us to overstate quality premiums to the extent that unemployment increases were inversely proportional to college quality. However, the recession in Texas was relatively mild: the average unemployment rate was 5.4\% between 2004-2006 and was 5.6\% between 2007-2009. In contrast, for the U.S. as a whole, the unemployment rate increased from $5.1 \%$ to $6.6 \%$ across these two periods. Furthermore, we show below that our results and conclusion are robust to including all earnings observations, not just those from those employed full-time. This finding suggests that recession-driven unemployment is not generating a misleading picture of earnings distributions in Texas.

We observe more than one quarter of earnings for all sample members. In order to generate one earnings estimate for each respondent, we stack log quarterly earnings observations (subject to the inclusion criteria above) and regress them on year dummies, quarter-of-year dummies, and a series of cohort dummies that indicate when an individual graduated from high school. We use the within graduate average of the residuals from this regression as the earnings measure in our empirical models. This method isolates the constant component of earnings for each individual over the period for which we observe his earnings and allows us to control for timeand cohort-specific shocks as well as for seasonality. 
The data from the TEA consists of both individual and high school level information. The individual level data include variables such as race/ethnicity, an indicator for whether the student has a college plan, participation in Title 1, whether the child receives free or reduced price meals, and the scores from the $11^{\text {th }}$ grade reading, writing, and mathematics sections of the Texas Assessment of Academic Skills (TAAS). Examples of the high school level data include enrollment, the ethnic composition of the school, and the percentage of the school that participates in talented and gifted programs. We obtain graduation status and timing from the THECB for each student as well.

The odd columns of Table 2 present summary statistics of individual characteristics for our analysis sample, separately by school type. As expected, the UT-Austin and TAMU graduates have higher high school test scores in every subject, and the community college students have the lowest average high school test scores. The flagship university graduates also are more likely to be in the top $10^{\text {th }}$ percentile of their school in each of these tests. The flagship universities have fewer black and Hispanic students than non-flagship universities and community colleges, and they also have a much smaller proportion of economically disadvantaged students. Overall, Table 2 demonstrates that students attending these different school types differ on important observable characteristics that are likely to affect earnings. Our empirical strategy described below seeks to eliminate the differences in the earnings distributions across sectors that are due to the differences in these observable characteristics.

A main limitation of the data we use is the fact that individuals only are in our sample if they graduated both from a Texas high school and a public Texas college. They also need to have at least three quarters of complete earnings data in Texas, which could be a limiting factor if students are in graduate school, if they leave the state or if they do not work. Because both UT-Austin and Texas A\&M have more of a national profile than other universities in Texas, if these graduates are more likely to take a job in another state or if they are more likely to be attending graduate school, then our earnings distributions will be biased. Especially if the most high-skilled students are those who leave the state, the Texas A\&M and UT-Austin earnings distributions will be biased downward. Furthermore, if college quality has an effect on the extensive margin of labor supply, it could create endogenous sample biases in our estimates. 
Table 3 shows the characteristics of those included and excluded from our analysis sample among graduates of each school type. Excluded observations are graduates for whom we never observe full time work. As the table demonstrates, those excluded from the sample are very similar to those included. Those who are in the top 10 percent of their high school class in reading and writing are slightly more likely to be excluded, but the difference is only 3 percentage points and this difference is present in all school sectors. Even within school type there are few differences in the observable characteristics of graduates included and excluded from the sample, and comparing the flagship and community college sectors to the non-flagship sector, there are no discernible differential patterns of exclusion. The fact that our sample is balanced with respect to whether earnings are present is summarized with the mean of predicted log earnings in Table 3. The predicted earnings are calculated by estimating a regression of log earnings residuals on all observable characteristics, separately by sector. We then predict log earnings using the resulting coefficients for the samples with and without earnings in each sector. As the estimates in Table 3 indicate, these means are extremely similar, which suggests that the sample of men for which we observe earnings is not systematically different from the sample of men for which we do not observe earnings.

Finally, at the bottom of Table 3, we show the number and proportion of students included and those excluded because they attend graduate school. While the proportion included declines across the table (and thus with observable college quality), particularly within the four-year sectors, the differences are not large. As the rest of the table shows, these different inclusion rates are uncorrelated with the rich set of observable characteristics in our data. The percentage of students excluded due to graduate school attendance also is very similar for UT-Austin and Texas A\&M, and it actually is slightly higher in the non-flagship sector. ${ }^{8}$ The sum total of the evidence in Table 3 indicates that the sample restrictions we make are unlikely to create systematic biases in our earnings distributions for each school type. Tabulations by race and ethnicity, which are available upon request, show that observable characteristics among included and excluded students by school type do not differ substantially either for any of these groups.

The critical missing variable in Table 3 is earnings; because our earnings data only cover

\footnotetext{
${ }^{8}$ This result may be due, in part, to the fact that we only observe graduate school attendance if it is within the state of Texas. More graduates from non-flagship universities who attend graduate schools probably do so in-state.
} 
Texas residents, we are unable to determine whether students who move out of Texas after graduating are higher (or lower) earners. This problem is particularly salient for the state flagships, where the most capable students may compete in a more lucrative national job market. In order to generate some information on earners among those who stay in Texas (and thus who are in our sample) and those who leave, we examine log earnings in the 2000 US Census among BA recipients who report having lived in Texas five years prior and who would have been of college age at the time (18-21). Panel A of Figure 1 shows the distribution of earnings in 2000 among BA recipients who are 23-26 and who lived in the Austin, TX MSA in 1995. The earnings distributions for those in Texas in 2000 versus those not in Texas in 2000 are virtually identical. Although there is a slight divergence at the top of the distribution, earnings are higher among those currently residing in Texas. A similar pattern holds for 23-26 year old BA recipients who lived in the College Station, TX MSA in 1995 (Panel B). While outof-state workers earned more at the bottom $20 \%$ of the distribution, ${ }^{9}$ the rest of the earnings distributions are very similar. We show below that the returns for Texas A\&M are highest for lower earners. Panel B of Figure 1 suggests we may understate these returns slightly because we are unable to observe earnings from Texas A\&M graduates who leave Texas. Finally, in Panel C, the earnings distributions for those who were in other areas of Texas are the same regardless of whether they currently live in Texas. ${ }^{10}$ Overall, Figure 1 presents little evidence of systematic attrition by higher or lower earning students, which suggests our inability to observe earnings for non-Texas-resident workers is not driving our results.

\section{Methodology}

The goal of this analysis is to estimate unconditional quantile treatment effects of college quality on earnings. This method differs from the conditional quantile treatment effects literature (Koenker and Bassett, 1978; Abadie, Angrist and Imbens, 2002; Chernozhukov and Hansen,

\footnotetext{
${ }^{9}$ The difference at the bottom of the distribution could be due to the inclusion of Blinn College students. Blinn College is a two-year school with a very high four-year transfer rate. If those students are lower earners and are more likely to remain in-state, the presence of these students in this sample could cause a divergence in earnings at the bottom of the distribution.

${ }^{10}$ We also do not find evidence of differences in the likelihood of having any earnings in the Census by school type. For example, the difference in the likelihood of having any earnings between UT Austin and other four-year graduates is -0.008 percentage points. For Texas A\&M, this difference is larger at about 4 percentage points, but this difference still is small relative to the large returns we estimate for Texas A\&M graduation. In addition, these differences are unadjusted for covariates, and if we were able to do control for the observables in our administrative data, we suspect there would be even smaller differences in labor force participation by school type.
} 
$2005)$ in the examination of treatment effects for each quantile of the marginal earnings distributions rather than the quantiles conditional on the covariates. The conditional quantiles are more difficult to interpret for policy purposes because they are unobserved, and thus conditional quantile treatment effects cannot be mapped simply into unconditional quantile treatment effects. We estimate the latter since we are interested in understanding how college quality affects the observed distribution of earnings. ${ }^{11}$

We estimate quantile treatment effects associated with graduation from each college sector relative to the public non-flagship four-year sector. We focus on graduation rather than attendance because graduation is the outcome most likely to be observed (and rewarded) by the labor market. Furthermore, estimates of the effect of college quality attended on earnings is complicated by the fact that many dropouts do not accumulate a lot of credits. So, even at high-quality schools, they will be relatively untreated by the university's quality. Since college quality is associated with higher rates of graduation, even conditional on student background characteristics and preparation for college (Bound, Lovenheim and Turner, 2010; Rouse, 1995), college graduates may constitute an endogenous sample. In Section 4.4, we show our results are robust to analyzing college attendees rather than graduates, particularly among four-year schools, but our main analysis focuses on graduates because we believe college graduation to be a more relevant post-secondary outcome for the labor market.

To estimate the quantile treatment effects of graduating from a particular college sector on earnings, first consider a two-sector higher education system where students choose to attend UT-Austin or a non-flagship, four-year university. Let $\mathrm{T}=1$ if the student graduates from UTAustin and $\mathrm{T}=0$ if not. As described in Firpo (2007), the quantile treatment effect on the treated for quantile $\tau$ can be written:

$$
Q T T=\left.q_{1, \tau}\right|_{T=1}-\left.q_{0, \tau}\right|_{T=1}
$$

The inference problem faced in this analysis is that the counterfactual quantile for the treated sample, $\left.q_{0, \tau}\right|_{T=1}$, is unobserved. In order to estimate $\left.q_{0, \tau}\right|_{T=1}$, we generate counterfactual earnings distributions that show what the earnings distribution would be among the untreated group

\footnotetext{
${ }^{11}$ See Angrist, Chernozhukov and Fernandez-Val (2006) for conditional quantile treatment effects of education on wages. Carneiro, Hanson and Heckman (2003) also show substantial heterogeneity and uncertainty in the returns to attending college.
} 
if the distribution of their observable characteristics were the same as in the treated group. Following DiNardo, Fortin and Lemieux (1996), each graduate can be described by earnings, $w$, a vector of observable characteristics, $x$, and a treatment status, $T$. The joint distribution of earnings and observables conditional on treatment status is given by:

$$
F(w, x \mid T=t)
$$

The density of earnings at each school type then can be calculated by integrating over the distribution of observable characteristics, separately by treatment status. For UT-Austin graduates, the earnings density can be written:

$$
\begin{aligned}
f(w \mid T=1) & =\int_{x} d F(w, x \mid T=1) \\
& =\int_{x} f\left(w \mid X=x_{1}, T=1\right) d F(x \mid T=1) \\
& \equiv f\left(w ; X=x_{1}, T=1\right)
\end{aligned}
$$

where $x_{1}$ is the distribution of observable characteristics among the treated. We want to estimate $f\left(w ; X=x_{1}, T=0\right)$, which is the counterfactual earnings distribution among those who were not treated that we would expect if their observable characteristics were identical to the observable characteristics of the treated group. DiNardo, Fortin and Lemieux (1996) show that:

$$
\begin{aligned}
f\left(w ; X=x_{1}, T=0\right) & =\int f(w \mid x, T=0) d F(x \mid T=1) \\
& =\int f(w \mid x, T=0) \psi(x) d F(x \mid T=0)
\end{aligned}
$$

where

$$
\psi(x)=\frac{d F(x \mid T=1)}{d F(x \mid T=0)} .
$$

Applying Bayes' rule, equation (5) can be written:

$$
\psi(x)=\frac{P(T=1 \mid x)}{P(T=0 \mid x)} * \frac{P(T=0)}{P(T=1)} .
$$


Because $p(T=1 \mid x)=1-p(T=0 \mid x)$, equation (6) is the odds ratio of the conditional likelihood of treatment and $\psi(x)$ are weights. Using our rich set of background characteristics, we use equation (4) to generate a counterfactual distribution of earnings that would have been expected if the observable characteristics of students who graduated from non-flagship public universities in Texas were distributed the same as the observables of UT-Austin graduates. ${ }^{12}$ This method is akin to the "aggregate decomposition" described in Firpo, Fortin, and Lemieux (2010). To our knowledge, this is the first analysis to use this reweighting method to estimate quantile treatment effects. ${ }^{13}$

The estimated quantile treatment effect then can be written as:

$$
Q T T=\left\{i n f_{q} P\left[f\left(w ; X=x_{1} ; T=1\right) \leq q\right] \geq \tau\right\}-\left\{i n f_{q} P\left[f\left(w ; X=x_{1} ; T=0\right) \leq q\right] \geq \tau\right\}
$$

Equation (7) is simply the difference between the unconditional quantiles of two marginal distributions: the observed treated distribution and the counterfactual untreated distribution. This difference identifies the quantile treatment effect for quantile $\tau$ under two assumptions. The first is "selection on observables:" the observable characteristics in our re-weighting function given by equation (6) must be sufficient to control for the fact that UT-Austin graduates have a different earnings distribution than non-flagship graduates because they have different characteristics that are rewarded by the labor market. The second assumption is rank permanence: the treatment must not change individuals' place in the earnings distribution. We discuss both of these assumptions in turn below.

In order to adjust the non-flagship public university earnings distribution for the fact that students who graduate from these universities differ systematically from UT-Austin graduates in ways that affect future earnings, we leverage the extensive information in our administrative data on student backgrounds. We estimate the following models of the probability a student graduates from a school in sector $j(j \in\{\mathrm{UT}$-Austin, TAMU, Community College $\})$ relative to

\footnotetext{
${ }^{12}$ This interpretation of this counterfactual earnings distribution also relies on the treated and untreated groups facing the same potential earnings structure. Given that these graduates all are working in the same state in the same time period, we believe this assumption is reasonable.

${ }^{13}$ Firpo (2007) discusses the feasibility of this approach for estimating quantile treatment effects, but he does not use this method.
} 
a non-flagship four-year university:

$$
I(j)_{i}=\alpha+\gamma X_{i}+\theta T_{i}+\phi E_{i}+\delta H S_{i}+\epsilon_{i}
$$

where $X$ is a vector of individual background characteristics, $T$ is a vector of high school test score controls, $E$ is a set of high school education variables, and $H S$ contains observed high school characteristics in the year the student graduated. The variables in $X$ are student ethnicity/race (white, black, Asian, Hispanic), Title I status, English proficiency, and free and reduced price lunch status. ${ }^{14}$ We include flexible controls for high school test scores, including quartics of student scores on the Texas state math, reading and writing standardized exams all students take in high school. Using the high school students attend, we also control for each student's relative rank within his or her school on each exam. Because we cannot observe GPA or class rank in our data, the relative rank variables control for the fact that higher-ranked students in each high school, conditional on test scores, are more likely to be admitted to higherquality schools. The vector $E$ contains information on high school educational programs, such as enrollment in gifted programs, special education, career and technology courses, whether the student had a college plan, and whether he was at risk of dropping out. Finally, we control for high-school variables that measure the educational environment from which students came. We include in equation (8) the ethnic composition of the high school, the percentage of students in each economic status group, the percentage of gifted students and students at risk, the percentage of title I eligible students, and total school enrollment. ${ }^{15}$

While the above description pertains to UT-Austin and non-flagship universities, we use the same methodology for each of the three "treatment" school types: UT-Austin, Texas A\&M and community colleges. For each treatment sector, we estimate a separate version of equation (8) that includes the same independent variables but that uses separate indicator variables for whether a student graduated from a school in a given sector relative to a non-flagship public school. All versions of equation (8) are estimated using logit models, and the predicted values

\footnotetext{
${ }^{14}$ Notably, we cannot observe parental education and income for many students. These variables come from college application material, and only the more selective schools asked students for this information. In Section 4.4, we show our estimates are robust to using these variables, however, suggesting that the detailed demographic characteristics in our model are sufficient to control for selection based on family background characteristics.

${ }^{15} \mathrm{We}$ also have controlled for high school fixed effects in some specifications. The drawback of high school fixed effects is that they perfectly predict UT and TAMU non-attendance for many schools. However, they are potentially powerful in controlling for unobserved student ability that is correlated with college sector and earnings. Estimates with school fixed effects do not produce qualitatively or quantitatively different answers and are discussed in Section 4.4.
} 
from these logit models are used to construct the weights shown in equation (6). ${ }^{16}$

In the even columns of Table 2, we show descriptive statistics for the non-flagship group that are weighted by the relative odds of graduating from each sector in Texas. Because our propensity score model contains a large number of variables and because we assume a logistic functional form, it is not assured that the methodology described above will balance each observable across treatment and control sectors. Comparing the even and odd columns in Table 2 , however, shows that our method fully balances the covariates in each sector; in no case is there a large or statistically significant difference between the observed mean and the re-weighted control group mean. At the bottom of the table, we calculate predicted log earnings in each sector using the observed graduates from that sector and all observed characteristics. We then predict log earnings for the treatment and control groups using the sector-specific coefficients. One can interpret these predicted log earnings as summary statistics of the difference between the characteristics of the treatment and control groups as they relate to earnings. As the table demonstrates, not only are the means identical among the treated and weighted control groups, but the distributions are the same as well. Thus, our propensity score model balances the covariates such that there is no predicted difference in the distribution of earnings across treatment and control groups. Any observed difference in the distribution of earnings must thus be due to school quality or to unobserved factors that are uncorrelated with the observables in our model.

The variables we include in our model we believe represent powerful controls for the fact that students of higher academic ability are more likely to attend a higher-quality school and to earn more. Although "student ability" is very difficult to account for perfectly, our flexible controls for standardized test scores in three different subjects, each student's place in their high school's test score distribution for each exam, and a detailed set of information about each student's high school composition and academic track are much stronger ability controls than have been used previously (Brewer, Eide and Ehrenberg, 1999; Black and Smith, 2004;

\footnotetext{
${ }^{16}$ Because students make one decision over a set of schools, it may be more appropriate to estimate the weighting function using a multinomial logit model of the choice between all college sectors. We have implemented this model for the choice among our three four-year public school sectors and the estimates, which are available upon request, are indistinguishable from those shown below. We only estimated this model using four-year schools due to the limited overlap in observable characteristics between flagship university graduates and community college graduates. We present results that use weights generated from treating each schooling decision as a binary choice between a given sector and the non-flagship public sector in order to be consistent across all "treatments" examined in this analysis, but our estimates are unchanged if we treat college sector choice among four-year sectors as a multivalued treatment.
} 
Black and Smith, 2006). Conditional on these observable characteristics, the critical remaining question is what drives the residual selection of students into colleges of differing quality. If these choices are based on unobservables that also are correlated with earnings potential, it will bias our estimates. Currently, there is little understanding of why students select different school types. Although students are sensitive to quality differences among schools (Long, 2004; Avery and Hoxby, 2004), this is not the only factor that matters. Choices also rely on idiosyncratic preferences (such as whether a relative attended the school, the quality of the campus visit, the quality of the sports teams in that year), the behavior of one's peers (i.e., whether many peers attend this school) and, in our data, the change in access to flagship universities that accompanied the implementation of the Top Ten Percent Rule in $1998 .{ }^{17}$ Due to the detailed set of controls for student academic ability and background we include in our model, we argue these three sources of variation are the predominant residual determinants of college sector selection. Crucially, these factors all are unlikely to be correlated with underlying earnings potential.

Variation in particular from the Top Ten Percent Rule is important to consider because it had a large change on the admissions regime in Texas. Unfortunately, our data do not include class rank, so we cannot exploit this change directly. However, post-1998, the data include an indicator of whether students are admitted to a given university under the Top Ten Percent Rule. This indicator on its own is highly predictive of attending UT-Austin and Texas A\&M. However, conditional on the relative test score rank controls in our model, this variable loses its predictive power, suggesting that controlling for relative rank on standardized tests is sufficient to account for the top $10 \%$ rule and for the effects of student relative rank on flagship admission. This result also suggests that our controls are indeed highly correlated with college sector choices of students. Furthermore, if we control for whether one is admitted through the Top Ten Percent Rule as well as interactions of all variables with a post-1998 indicator variable,

\footnotetext{
${ }^{17}$ The Top Ten Percent Rule - Texas House Bill 588 - is an admissions algorithm. It grants automatic admission to any public college or university in Texas to Texas high school graduates who finish in the top decile of their graduating class and apply to college within two years of finishing high school. Texas House Bill 588 also permits each college or university to decide, on an annual basis, whether or not to offer automatic admission to students who finish in the top quartile. The law further lists characteristics that public universities can use in making admissions decisions. Examples of such factors include the applicant's socioeconomic background, the performance level of the applicant's high school, the financial status of the applicant's school district, parental income, parental education, and whether the applicant has bilingual proficiency. Prior to 1998, admissions included affirmative action considerations, which allowed colleges to consider factors such as the applicant's race, academic performance, class rank, curriculum, and standardized test scores. To our knowledge, there were no strict formulas relating these factors to admission decisions.
} 
our estimates are unchanged. ${ }^{18}$ Thus, there is little evidence in our data that the imposition of the Top Ten Percent Rule biases our estimates by altering the relationship between student ability and college choice in a manner that we cannot measure.

In addition to the factors discussed above, it also is possible that unobserved factors, such as "student motivation" or "non-cognitive" skills that are related to earnings also drive some of the college quality variation. We believe our estimates are inconsistent with the existence of biases from these omitted variables because of the small effect of our observables on earnings distributions, because of the different shapes of the quantile treatment effects across school types, and because of the robustness of our estimates to controlling for factors that are likely to be correlated with these unobservables, such as parental income and education as well as high school fixed effects. With observational data, it is not possible to control directly for these difficult-to-measure student attributes, which highlights the importance of studies that use natural experiments with exogenous school quality variation (e.g., Hoekstra, 2009). Such natural experiments are exceedingly rare, however, which necessitates using observational data with extensive student background controls. That our mean estimates are similar to, if somewhat smaller than, the estimates from previous work (see Table 4) suggests these variables are sufficient to control for the selection of students with higher earnings power into high-quality colleges.

As implied by equation (6), the estimated propensity scores must be less than 1 because the weights are not defined for those who are predicted with certainty to attend a given type of college. ${ }^{19}$ Our propensity score models generate predicted probabilities of less than one for every individual in our sample. Similar to matching estimators, there also must be overlap of the propensity score distributions among the treated and control observations. ${ }^{20}$ Without overlap of the propensity scores, there will be individuals in the treated group for whom there are no observably equivalent individuals in the control group. Thus, it would not be possible to construct a counterfactual earnings distribution that would occur if the distribution of observables in the control group was the same as in the treated group because there would be parts of the joint distribution of observable characteristics in the treated group that are absent

\footnotetext{
${ }^{18}$ These estimates are available from the authors upon request.

${ }^{19}$ Note as well that those with zero predicted likelihood of attending each college type will receive a weight of zero. These observations are effectively excluded from the analysis, which is why we are estimating treatment effects on the treated.

${ }^{20}$ See Smith and Todd (2005) for a detailed discussion of this issue with respect to matching estimators.
} 
in the control group. The presence of such non-overlap in observable characteristics will cause a bias in the estimation of the counterfactual earnings distributions.

Figure 2 presents estimated propensity scores from equation (8), estimated for each school type separately with the non-flagship universities as the control group. Each panel shows the number of individuals in each grouping of estimated propensity scores among treated and control observations. Due to confidentiality concerns, we are unable to present means calculated with fewer than 10 individuals, so these propensity score groups are the smallest equal-sized bins we could construct between 0 and 1. For no school types are there gaps in the estimated propensity scores, and even for those who have very high and low estimated probabilities of attending each school type there are those in the same propensity score range in both the treated and control groups. Although our propensity score models are based on a large number of observable characteristics that are designed to control for student selection into different school quality types, we have sufficient overlap of the predicted likelihood of treatment among treated and control groups to estimate equation $(7) .{ }^{21}$

The second assumption needed to estimate quantile treatment effects in this setting is rank permanence (Doskum, 1974; Lehmannn, 1974; Firpo, 2007; Bitler, Gelbach and Hoynes, 2006). Rank permenance imposes the condition that the treatment does not change an individual's relative place in the distribution of earnings. We believe this assumption is reasonable in the context of this analysis because, conditional on the selection on observables assumption holding, any rank switches would have to be symmetric. For example, if a flagship graduate at the $50^{\text {th }}$ percentile of the earnings distribution would have been in the $80^{\text {th }}$ percentile if he had graduated from a non-flagship, if the selection on observables assumption is valid then another student at the $80^{\text {th }}$ percentile of the UT distribution would have to be at the $50^{\text {th }}$ percentile if he graduated from a non-flagship. Though possible, there is little reason to believe such rank switching should occur due to differences in college quality. Furthermore, as Bitler, Gelbach and Hoynes (2006) stress, even without the rank preservation assumption, we are able to estimate the effect of

\footnotetext{
${ }^{21}$ Flores and Mitnik (2009) present a method for generating common support among treatment and control groups when there are multiple treatments. They emphasize that in order to compare estimates for different treatments, the same sample with general common support needs to be used. Their method is to delete observations sequentially that are not in the common support for each treatment, such that the final sample is the sample for which there is support with respect to each treatment individually. Because we do not exclude any observations for any treatment due to the lack of common support among treatment and controls, this sequential support method leaves exactly the same analysis sample as we use in the analysis. Because of this feature of our data, comparisons of the quantile treatment effects across treatment sectors are valid.
} 
college quality on the entire distribution of earnings. That is, our estimates show how college quality affects each quantile of the earnings distribution regardless of whether rank permanence holds. This distributional change is what is needed for welfare analysis, and we are the first in the literature to estimate how college quality affects the earnings distribution. ${ }^{22}$ While we focus on estimating quantile treatment effects, an additional value of our methodological approach is that the effect of college quality on the earnings distribution is estimated as well. Thus, even without the rank permanence assumption, our estimates are of general policy interest.

\section{Results}

\subsection{Earnings Distributions}

Figure 3 shows the observed earnings distributions for each treatment-control grouping as well as the counterfactual earnings distributions if the observable characteristics in the non-flagship schools were the same as in each of the treatment sectors. Comparing the observed earnings distribution in the treated schools and the counterfactual control school distributions shows the effect of college quality on the entire distribution of earnings, which does not require assumptions about rank permanence.

As shown in Panel A, the UT-Austin distribution is above the counterfactual non-flagship distribution, and this difference grows as one moves higher up in the earnings distribution. Thus, under the assumption that our observable characteristics are sufficient to control for selection of different-skilled individuals into higher quality universities, Panel A of Figure 3 indicates that graduating from UT-Austin shifts out the earnings distribution and that this shift is larger higher up in the distribution.

In Panel B, we show similar distributions among Texas A\&M graduates and non-flagship public university graduates. As with UT-Austin, the Texas A\&M earnings distribution is above the counterfactual control group distribution, but here, the outward shift is more uniform. To the extent there is change in the shape of the distribution, it is a flattening of the distribution due to larger returns at the lower end than at the upper end.

Graduating from a community college rather than a four-year non-flagship public university

\footnotetext{
${ }^{22}$ See Heckman, Smith and Clements (1997) for a discussion of heterogeneous treatment effects and social welfare.
} 
has a substantial effect on the shape of the earnings distribution. For nearly the entire distribution of earnings, earnings for community college graduates are below those of non-flagship public university graduates. However, the estimates steadily asymptote towards zero as we move across the earnings distribution. Graduating from a community college is particularly deleterious for the bottom of the distribution. These estimates are suggestive that the previous literature that estimates negative effects of community college attendance or graduation on earnings is driven by the lower part of the earnings distribution (Reynolds, 2009; Kane and Rouse, 1995).

In all three panels of Figure 3, the counterfactual earnings distributions are quite similar to the observed other 4-year distributions. The difference between these distributions can be interpreted as the contribution of observable differences among students in each schooling sector to the differences in earnings across sectors. ${ }^{23}$ That the controls explain so little of the observed earnings differences across school sectors is suggestive that the differences in earnings across school types is not being driven by selection on unobserved components of student ability. Given the comprehensive set of covariates included in the propensity score models, one would expect these variables to explain a large proportion of the observed earnings differentials across school types if the returns to college quality were small and the ability/skill differences were driving the observed earnings differences. Unobserved factors that are correlated with both college quality and earnings, such as non-cognitive skills and student academic ability, would have to be uncorrelated with our extensive set of controls and highly correlated both with school sector choice and subsequent earnings to be significantly biasing our estimates. But, these unobservables are likely to be correlated with the background, school environment and test score measures in the propensity score models. Thus, that our observable variables explain little of the observed earnings differences across school types is suggestive that it is the college environment that is causing the shift in earnings distributions shown in Figure 3 rather than unobserved factors correlated with both college quality and earnings.

\footnotetext{
${ }^{23}$ This decomposition interpretation assumes that the effect of each observable is the same in each school type. For example, the effect of a 1 standard deviation change in math test scores is assumed to be the same for a student who graduates from UT-Austin as for a student who graduates from a non-flagship 4-year university.
} 


\subsection{Quantile Treatment Effect Estimates}

Before estimating the quantile effects, it is instructive to examine mean effects of college quality on earnings as a point of comparison with the rest of the literature. Table 4 shows estimated mean impacts, regressing log earnings residuals on treatment indicators while adding in controls sequentially. We add in the controls in this manner in order to show how correlated they are with school type and with earnings. We first show estimates from bivariate regressions, and the mean effects all are large and statistically significantly different from zero at the $1 \%$ level. When we add in our test score controls, the estimates become smaller in absolute value, suggesting these test scores measures are able to control for at least some of the selection on student ability that drives the large bivariate estimates. We then add in student demographic characteristics and school experience controls (i.e., limited English proficiency, gifted and talented, at risk for dropping out) and finally include school average demographic characteristics. These variables all attenuate the estimates further, although conditional on the test score controls the other variables do not have large impacts on the estimates. We interpret this as evidence that our test score measures are powerful controls for selection into school types, because the demographic, school experience and school composition variables all are correlated with college sector and with future earnings. ${ }^{24}$ These correlations are mostly in common with the test scores, however, which highlights the value of our set of test controls in this analysis.

Focusing on the estimates with a full set of controls, the mean effect for UT-Austin is $11.5 \%$. This estimate is somewhat smaller than in previous work that estimates the returns to attending an elite public university, ${ }^{25}$ however it is still positive, statistically different from zero at the $1 \%$ level, and sizable in magnitude. The mean effect for Texas A\&M relative to non-flagship public universities is much higher, at $21.2 \%$. This estimate is similar to the results from the existing literature. Finally, for community colleges we estimate a mean effect of $-10.0 \%$ on earnings, which is somewhat larger in magnitude relative to previous findings of the effects of community

\footnotetext{
${ }^{24} \mathrm{~A}$ pooled regression of log earnings on our full set of non-school-type controls for all Texas graduates in our sample yields an $\mathrm{R}^{2}$ of 0.06 . Thus, our observable characteristics explain a non-trivial proportion of the earnings variation.

${ }^{25}$ Hoekstra (2009) estimates the earnings effect of attending an un-named flagship state university is $24 \%$. Brewer, Eide and Ehrenberg (1999) estimate a mean return of $26 \%$. Note that both of these papers focus on attendance, while we examine the effect of graduation. This difference may reduce our estimates if part of the return to attending a flagship university is increasing the likelihood of finishing. Furthermore, in the Hoekstra (2009) analysis, the counterfactual for those not attending the flagship is a mix of lower-ranked four-year attendance, community college attendance, and non-college attendance. This counterfactual may cause the estimated earnings returns to be higher than if a counterfactual of non-flagship four-year universities is used. Similarly, in Brewer, Eide and Ehrenberg (1999), the counterfactual is "bottom public" universities, which are likely to be of lower quality on average than the non-flagship public universities in Texas. This will serve to increase the estimated earnings returns.
} 
college enrollment on earnings. ${ }^{26}$ Overall, the similarity of our mean estimates to prior work is inconsistent with the existence of large biases due to unobserved student attributes in our results. But, we emphasize that this conclusion is only suggestive due to the sample differences and the differences in counterfactuals that make cross-study comparisons difficult.

The motivating question of this analysis is to understand how well these mean effects characterize the returns to quality experienced by most students. We now turn to quantile treatment effects to estimate the distribution of returns rather than just the mean. The quantile treatment effects of college quality on earnings from estimation of equation (7) are shown in Figure 4. In each panel, the solid line is comprised of 99 quantile treatment effects for each percentile between 1 and 99 that are the difference between the observed UT-Austin/TAMU/community college distributions and the associated counterfactual other 4-year earnings distributions. The dashed lines show the bounds of the $95 \%$ confidence intervals that are estimated by bootstrapping the entire estimation procedure and plotting the $2.5^{\text {th }}$ and $97.5^{\text {th }}$ percentiles of the bootstrapped earnings differences at each percentile. Quantile treatment effects for each $5^{\text {th }}$ percentile of the distribution together with bootstrapped confidence intervals are shown in column (i) of Tables 5-7 for UT-Austin, Texas A\&M and community colleges, respectively. Finally, the horizontal dotted lines are the $95 \%$ confidence intervals of the mean estimates from the "All Controls" specification shown in Table 4.

As shown in Panel A of Figure 4, the mean estimates do a poor job of characterizing the earnings premiums experienced by most UT-Austin graduates: the quantile treatment effects are outside the mean confidence interval for over $70 \%$ of the distribution. The effect of UTAustin graduation relative to non-flagship graduation is decreasing in the first decile, from $12.0 \%$ to $3.4 \%$. However, these estimates are not statistically different from zero at the $5 \%$ level. After the $10^{\text {th }}$ percentile, the returns to UT-Austin graduation increase dramatically across the earnings distribution. From the $10^{\text {th }}$ percentile return of $3.4 \%$, the returns increase to $6.3 \%$ at the $25^{\text {th }}$ percentile, $12.1 \%$ at the median, $16.8 \%$ at the $75^{\text {th }}$ percentile, and are over $19 \%$ above the $90^{\text {th }}$ percentile. The returns are largest at the $97^{\text {th }}$ percentile, at $31.6 \%$. Thus, across most of the earnings distribution, the returns to UT-Austin graduation increase

\footnotetext{
${ }^{26}$ Reynolds (2009) estimates a decline in earnings of about $5 \%$ due to community college relative to four-year attendance. Kane and Rouse (1995) find that community college and four-year credits are equally valued by the labor market but that community college students earn less than four-year students because they earn fewer college credits.
} 
with one's place in the earnings's distribution, suggesting that this university is particularly lucrative for relatively higher earners.

The shape of the returns to Texas A\&M graduation in Panel B is much different from the UT-Austin graph. For Texas A\&M, the highest returns are at the bottom of the distribution, with a return of $36.4 \%$ at the $1^{\text {st }}$ percentile. While the estimates at the lowest part of the distribution are not very precisely estimated, the lower bound of the $95 \%$ confidence interval is $25.4 \%$ at the $1^{\text {st }}$ percentile and the bottom $20 \%$ of the distribution is larger than the upper confidence interval bound of the mean. The returns decline until the $30^{\text {th }}$ percentile, where they are $20.6 \%$. They remain fairly stable between the $28^{\text {th }}$ and $90^{\text {th }}$ percentiles, ranging between 17.6 and 21.8 percent, after which they increase to $22.8 \%$ at the $99^{\text {th }}$ percentile. The mean accurately characterizes the earnings premium for Texas A\&M for the majority of the distribution. The returns to TAMU graduation are clearly much more stable than for UT-Austin graduation. The standard deviation of the returns across quantiles in Panel B is 0.037, while in Panel A it is 0.066 (a $78 \%$ difference in the standard deviations).

That the slope of returns with respect to earnings is opposite for Texas A\&M relative to UTAustin is further evidence against biases from omitted student characteristics. For example, it might be the case that those at the top of the earnings distribution are more motivated, attend higher-quality schools, and earn more. While such a story would explain the upward sloping returns at UT-Austin, it cannot explain why the returns largely decline with earnings at Texas A\&M, especially because students at the two flagship schools are similar on observables (see Table 2). Similarly, if student motivation is a substitute for college quality, it should produce the pattern of returns for TAMU but not the one observed at UT-Austin. In short, we view the different shapes of earnings premia across the two flagship schools as evidence against large biases from omitted variables, because these omitted variables are likely to be distributed similarly across the income distribution in the two schools, which would force the earnings patterns to be similar.

A question of interest then is why the Texas A\&M estimates are different than those for UT-Austin. As Tables 1-3 show, the observable characteristics of these two flagship schools and the students who graduate from them are similar. However, students who graduate from 
these schools major in very different subjects, as shown in Figure 5. For example, over $44 \%$ of the undergraduate degrees awarded at Texas A\&M are in engineering and agriculture, whereas only $19 \%$ of the degrees awarded to undergraduates at UT-Austin are in those subjects. In contrast, $62 \%$ of the degrees at UT-Austin are in liberal arts, social sciences, communication, math/computer science and science, while only $36 \%$ of the undergraduate degrees awarded by TAMU are in these subjects. Using the same log earnings residuals used in the quantile treatment effect estimates for all male college graduates in Texas, Table 8 shows that agriculture and engineering majors earn more on average but have a lower variance of earnings than those in the majors favored by UT-Austin graduates. Consequently, when we control for college major dummies in the weighting logits, the differences in the quantile treatment effect estimates between Texas A\&M and UT-Austin largely disappear. These estimates are shown in Figure 6 along with the associated mean confidence interval bands. While the Texas A\&M distribution is very similar to the one shown in Panel B of Figure 4, the bottom of the UT-Austin distribution has been shifted upward significantly. Although the earnings premia at the top of the UTAustin distribution still are higher than at Texas A\&M, from an accounting standpoint, the vast majority of the differences across the flagship universities can be explained by differences in college majors, with UT-Austin students majoring in areas that have lower average earnings and higher earnings variance. Of course, major selection is itself endogenous, and we are hesitant to draw too strong a conclusion from Figure 6 because of the strong assumption embedded in these estimates that our controls are sufficient to account for the selection of students into majors across schools. ${ }^{27}$ But, these estimates are suggestive that both quality of the school as well as one's major is very important in driving college quality premiums. That the returns to both flagships are universally positive and are almost universally statistically different from zero at the $5 \%$ level suggests that all students graduating from either school can expect positive gross earnings returns to the investment. However, the size and variance of the expected premium is a function of one's major as well.

In Panel $\mathrm{C}$ of Figure 4, we show the effect of graduating from a community college relative to

\footnotetext{
${ }^{27}$ Arcidiacono (2004) finds large differences in returns to different majors and argues that much of the ability sorting is due to student preferences rather than monetary returns. However, Arcidiacono, Hotz and Kang (2011) and Wiswall and Zafar (2011) both find evidence from direct surveys of students about subjective beliefs regarding returns to and preferences for majors that expected returns are a driver of student preferences for majors. These findings highlight the difficulty in interpreting the estimates in Figure 6 as causal, but they still are interesting as descriptive evidence of the importance of college majors for the distribution of earnings differentials across college sectors.
} 
graduating from a non-flagship public university on the distribution of earnings returns. The estimated effect of community college graduation increases across the earnings distribution. The estimates are negative and statistically significant below the $84^{\text {th }}$ percentile, ranging from $-21 \%$ to $-1 \%$. From the $85^{\text {th }}$ through the $91^{\text {st }}$ percentiles, the returns continue to be negative, but they are small in magnitude and are not statistically differentiable from zero. The returns for the $92^{\text {nd }}$ through the $97^{\text {th }}$ percentiles are positive, with the returns for the $95^{\text {th }}$ and $96^{\text {th }}$ percentiles being statistically different from zero at the $5 \%$ level. While these positive estimates are relatively small in magnitude, the results in Panel $\mathrm{C}$ suggest that the earnings penalty from community college versus non-flagship four-year graduation only applies to the lower part of the earnings distribution. ${ }^{28}$ In addition, the mean estimate of $-10.0 \%$ is a very imprecise estimate of the expected return for a randomly selected community college graduate. Those lower in the earnings distribution experience a much higher penalty, and those at the top experience similar earnings to non-flagship graduates. Given the large price differences between the twoyear sector and the four-year sector, which the tuition estimates in Table 1 likely understate due to the higher prevalence of commuter students at community colleges, the results in Panel $\mathrm{C}$ of Figure 4 suggest that it may be optimal for a non-trivial proportion of students to attend a community college in Texas rather than a four-year non-flagship university in Texas. ${ }^{29}$

An important question in seeking to understand who benefits from graduating from a more elite college is whether the earnings premium varies across the socioeconomic distribution. Although we do not observe parental income for a proportion of our sample, we can observe student race and ethnicity, which is correlated with socioeconomic status. Due to the large disparities in higher education attainment for African American and Hispanic students relative to white and Asian students, the differential returns to college quality faced by these groups are of much interest. Such differences could be driven by mismatch, ${ }^{30}$ differences in academic

\footnotetext{
${ }^{28} \mathrm{It}$ is very unlikely that the relatively higher returns at the top of the distribution for community colleges are due to transferring. Recall that these estimates are for graduates, so any transfers to four-year schools who obtain a BA are counted as four-year graduates in our analysis. If some of the community college graduates transfer to a four-year school but do not obtain a BA, their earnings could increase. But, they still likely would earn less than comparable BA recipients, which is at odds with the equivalent earnings of non-flagship four-year and community college graduates at the top of the earnings distribution shown in Figure 4.

${ }^{29}$ Note that controlling for majors in the community college estimates is difficult, because many community college degrees are in areas that are not offered in four-year schools. Thus, we do not estimate community college models with major controls as we do for the public flagships.

${ }^{30}$ Arcidiacono et al. (2011) shows evidence from Duke University that affirmative action leads to mismatch based on private information that the university has about students. Cortes (2010), however, finds little evidence that the Texas Top Ten Percent Rule led to changes in minority graduation rates and persistence due to mismatch. Rothstein and Yoo (2008) also find little evidence of affirmative action-based mismatch in law school.
} 
preparation for college, differences in major selection, and labor market discrimination. Most previous work has not been able to identify how college quality earnings premiums vary across racial and ethnic backgrounds because of data limitations. Despite the fact that the proportion of black and Hispanic students at UT-Austin and Texas A\&M is low (see Table 2), we are able to present some of the first evidence of college quality returns for these groups.

\subsection{Quantile Treatment Effects by Race/Ethnicity}

Table 4 presents mean effects of college sector on earnings for white, black, Asian and Hispanic students. At UT-Austin, white and Asian students have the highest mean returns, at about $12.9 \%$ and $13.8 \%$, respectively. Black and Hispanic students experience the lowest earnings premiums $-3.4 \%$ for black graduates and $3.5 \%$ for Hispanic graduates. The mean return for Hispanic students is statistically different from zero at the $5 \%$ level, while the mean for black graduates is statistically indistinguishable from zero. At Texas A\&M, however, the mean returns are both higher and more similar across groups, ranging from $17.9 \%$ to $21.9 \%$. The differences between the earnings premiums for black and Hispanic students across UT-Austin and TAMU mirror those for the whole sample show in Section 4.2. Among white, black and Hispanic community college graduates, the returns are between $-8.5 \%$ and $-12.3 \%$. However, for Asian students, the average earnings penalty for community college graduation relative to non-flagship public four-year graduation is $-27.1 \%$.

These mean estimates are suggestive of a large amount of heterogeneity across sector and student groups in the returns to college quality. We now present quantile treatment effects for each sector and student race/ethnic group to examine how well these mean effects describe the earnings premiums for these students. Estimates for each decile along with bootstrapped $95 \%$ confidence intervals are shown in Appendix Table A-1. ${ }^{31}$

Figure 7 shows quantile treatment effect estimates for UT-Austin separately for white, black, Asian and Hispanic graduates. The distribution of returns for white students is very similar to the overall sample. For black graduates, who are shown in Panel B, the estimates are generally higher than for white graduates below the $20^{t h}$ percentile. Although the standard

\footnotetext{
${ }^{31}$ We also have generated propensity score distributions akin to Figure 2 separately by race and school type. These distributions show that there is common support between treatment and control across all school types and race and ethnic groups. These graphs are available from the authors upon request.
} 
errors are large, the point estimates for the $1^{\text {st }}$ to the $4^{\text {th }}$ percentiles range from $44.0 \%$ to $73.7 \%$. The returns for black UT graduates are much lower for the remainder of the distribution and generally are indistinguishable from both the mean and from zero: between the $11^{\text {th }}$ and the $90^{t h}$ percentile, the estimates range from about $-4 \%$ to $10.5 \%$. While the returns rise for the top decile, the estimates still are imprecisely estimated. These results are suggestive that it is black graduates at the top and bottom of the earnings distribution who experience sizable earnings premiums due to UT-Austin graduation; for the rest of the distribution the returns are small. ${ }^{32}$

The returns to UT-Austin are universally high for Asian graduates, ranging from a minimum of $8.5 \%$ to a high of $42.3 \%$. As with black students, the returns for Asian graduates are highest at both the bottom and top of the earnings distribution. Unlike black graduates, however, the estimated quantile treatment effects are - for the most part-statistically different from zero. In contrast, earnings premiums for the lowest Hispanic earners are small, often with negative coefficients that are not statistically distinguishable from zero. The estimates then rise; they become consistently positive above the $30^{\text {th }}$ percentile and become statistically significant at the $50^{\text {th }}$ percentile. The estimates take on a value of $4.5 \%$ at the median and reach a high of $33.2 \%$ percent at the $99^{t h}$ percentile. Especially for white and Hispanic students, the mean estimates do a poor job of characterizing the quality earnings premium students experience. And, for historically under-represented minorities, while the average returns are rather low, for portions of the earnings distribution they are quite large.

Similar to the estimates in Figure 4, the estimates across all four groups exhibit less variability for Texas A\&M than for UT-Austin, as shown in Figure 8. Again, the white distribution is very similar to the overall distribution shown in Figure 4, which is not surprising given that Texas A\&M is over $88 \%$ white. For black graduates, the returns at the bottom of the distribution are very high. They decline across the distribution of earnings, going below $30 \%$ at the $16^{\text {th }}$ percentile and remaining between $10.8 \%$ and $27.8 \%$ for the remainder of the distribution. Earnings premiums for Asian graduates of Texas A\&M are high in the lower tail of the the distributions as well. The maximum estimate is at the $4^{\text {th }}$ percentile, with a value of approx-

\footnotetext{
${ }^{32}$ Note that the distribution of majors is remarkably similar across race and ethnic groups, such that differences in majors across groups are unlikely to account for the differences in estimated returns. Major distributions are available from the authors upon request.
} 
imately $50 \%$. The estimates decline below $20 \%$ at the $12^{\text {th }}$ percentile, remain between $13.2 \%$ and $19.3 \%$ for the $13^{\text {th }}$ through the $89^{\text {th }}$ percentiles and climb above $20 \%$ as we move into the top decile. The treatment effects for Hispanic graduates from TAMU follow a pattern similar to the returns for Asian graduates. The largest treatment effect occurs at the $2^{\text {nd }}$ percentile, a value of $36.7 \%$; the earnings drop below $20 \%$ at the $11^{\text {th }}$ percentile, remain between $15.2 \%$ and $19.6 \%$ for the $12^{\text {th }}$ through the $95^{\text {th }}$ percentiles, and exceeds $20 \%$ for the $96^{\text {th }}$ through the $99^{\text {th }}$ percentiles.

Figure 9 shows earnings penalties from finishing at a community college rather than finishing at a four-year non-flagship university stratified by race and ethnicity. We obtain negative estimates of the returns to graduating from a community college for whites from the $1^{\text {st }}$ percentile to the $93^{r d}$ percentile, with the estimates from the $3^{\text {rd }}$ percentile to the $78^{\text {th }}$ percentile being statistically significantly different from zero. The returns rise as we move across the distributions of earnings, become positive but statistically insignificant at the $93^{\text {rd }}$ percentile, and fall below zero at the $96^{\text {th }}$ percentile. The distribution of returns for black community college graduates relative to their four-year non-flagship counterparts follow a similar pattern to that of the returns white community college graduates experience. Black community college graduates experience negative returns from the $1^{\text {st }}$ percentile to the $91^{\text {st }}$ percentile, with the estimates from the $7^{\text {th }}$ percentile to the $86^{\text {th }}$ percentile being statistically significant. Relative earnings rise as we move across the distributions of earnings; they are positive, rising, and statistically insignificant between the $91^{\text {st }}$ and $96^{\text {th }}$ percentiles and become statistically significant for the $97^{t h}$ percentile and above. The positive returns at the top of the distribution are large, reaching $15.5 \%$ at the $99^{\text {th }}$ percentile. Thus, while most black community college graduates earn less than their counterparts at four-year non-flagship universities, for the very top of the earnings distribution this relationship is reversed. Adding in the lower time and direct costs of community colleges, the net returns to community college graduation are likely positive for much of the upper portion of the earnings distribution for black college graduates.

The community college returns are almost universally negative for Asian students, and although the confidence intervals are large, the negative returns are more pronounced in the lower part of the earnings distribution. As with whites, the low mean community college returns are 
driven predominantly by the lowest earners. The distribution of returns for Hispanic students, however, are quite similar to those for black students. The returns are negative below the $84^{\text {th }}$ percentile and then are positive and statically significantly different from zero at the $96^{\text {th }}$ percentile and above. For the top decile of the distribution, the returns to community college graduation are between $2 \%$ and $6 \%$. While typically lower than the returns for the African American sample, these results point to positive gross (and thus higher net) returns to community college enrollment for high-earning Hispanic students. The finding that mean returns are negative but are positive for the upper portion of the distribution of earnings, particularly for black and Hispanic students, highlights the importance of examining the entire distribution of returns rather than focusing on just the mean returns. In particular, the lower mean returns for black and Hispanic students relative to white students shown in Table 4 mask the fact that returns are lower for these groups at the bottom of the distribution but are larger at the top.

\subsection{Robustness Checks}

As discussed in Section 3, the validity of our estimates rests on the ability of the observable characteristics in our model to control for the selection of students with higher underlying earnings power into higher-quality schools. In this section, we assess the robustness of our estimates to several different modeling assumptions. First, we include high school fixed effects in the propensity score model. Because one's high school likely is correlated with unobserved ability, motivation and non-cognitive skills, these results will lend insight into remaining selection bias in our preferred estimates. The drawback of this model is that we lose many control group observations because there are numerous high schools in Texas that send no students to Texas A\&M and $\backslash$ or UT-Austin. Column (iii) of Tables 5-7 contains the quantile treatment effects for this model, and for all three school types the estimates are virtually identical to those without high school fixed effects (column (i)).

While our data contain a rich set of covariates with which to control for selection, we do not include parental income and education in our baseline estimates. This omission stems from the large volume of missing data for these variables due to the fact that only students who apply to elite schools in Texas are required to supply such information. In columns (iv) and (v) of 
Tables 5 and 6 , we show estimates for the sample of students that have parental income and education data but excluding these variables (column (iv)) and then for this sample including these variables (column (v)). We are unable to do this robustness check for community college students because too few students provide parental background information. However, as Tables 5 and 6 show, the estimates for the sample of students who provide this information are virtually unchanged when parental income and education are included or excluded. Furthermore, despite the endogeneity of the reporting of these variables, the estimates for this sample are very similar to the baseline estimates. Given the strong correlation between family background, schooling and earnings, that adding parental education and income does not influence the quantile treatment effect estimates suggests that our controls do a good job of controlling for the selection of more earnings-capable students into higher-quality colleges.

Due to the structure of our data, the earnings data we use for this analysis come from earnings when graduates in our sample are in their mid 20s and early 30s. However, if college quality affects the returns to experience, examining earnings differences for recent graduates may yield misleading estimates of the effect of college quality on long-run earnings. In order to examine whether our estimates are sensitive to the timing of when earnings are measured, column (ii) of Tables 5-7 show quantile treatment effects using the oldest cohorts: those who graduate between 1996 and 1998 and thus who are between 27 and 31 years old in 2007-2009 when earnings are measured. These students also are unaffected by the Texas Top Ten Percent Rule, so these estimates provide a check that this admissions regime change does not seriously bias our estimates. For UT-Austin (Table 5) and Texas A\&M (Table 6), the estimates using the older sample match the estimates from the whole sample very closely above the $40^{\text {th }}$ percentile of the earnings distribution. Below the $40^{\text {th }}$ percentile, the older workers experience slightly lower returns, suggesting that our baseline sample understates the amount of heterogeneity in returns. For UT-Austin, the estimates are negative below the $15^{\text {th }}$ percentile; however, these estimates are statistically insignificant. Aside from the estimates below the $15^{\text {th }}$ percentile for UT-Austin, the quantile treatment effects of UT-Austin and Texas A\&M graduation are similar for the 1996-1998 sample and for the full sample.

Among community college graduates, the differences are somewhat larger between the two 
samples, as shown in column (ii) of Table 7. As with the estimates for TAMU and UT-Austin, the estimates for the 1996-1998 sample are below those for the full sample at the bottom of the distribution. Between the $10^{\text {th }}$ and $65^{\text {th }}$ percentiles, the estimates are very similar. However, above the $65^{\text {th }}$ percentile, the early cohort estimates approach zero and then become more negative at the very top, while the full sample estimates approach zero higher up in the distribution. Despite these differences, these estimates are qualitatively similar, and the differences in magnitudes of the returns at the top of the earnings distribution are small. Using the early cohort versus the full sample does not alter the main conclusions drawn from the community college results that for the upper portion of the earnings distribution the returns to community college graduation relative to four-year non-flagship graduation are close to zero and likely are positive once one accounts for the cost differences across school types.

We also examine the effect of college attendance rather than college graduation on subsequent earnings. On the one hand, college attendance is a compelling margin to examine because college sector can affect the likelihood of graduation (Bound, Lovenheim and Turner, 2010; Rouse, 1995). On the other hand, college graduation is more appropriate because this is the more salient signal for employers and because examining only enrollment means the intensity of treatment varies significantly across individuals based on how many credits they receive. Furthermore, for community college students, the graduate sample is likely to be much more similar to BA recipients than is the attendee sample, as many community college students who drop out have loose attachments to the postsecondary sector and do not intend to obtain a BA.

Column (vi) in Tables 5-6 and column (iv) in Table 7 show results when we use all college attendees and assign school types based on the institution in which each individual earned the most credits. ${ }^{33}$ For UT-Austin and Texas A\&M graduates, the results using attendees are similar to those using graduates. The main differences come at the bottom of the distributions, where the returns for attendees are around 3-5 percentage points higher. But, the main qualitative and quantitative results remain, with the returns for UT-Austin students increasing across the income distribution and the returns for Texas A\&M students declining. ${ }^{34}$

For community college attendees, there is more of a divergence from the baseline estimates.

\footnotetext{
${ }^{33}$ Estimates are very similar when we assign students based on the first college attended after high school.

${ }^{34}$ Appendix Table A-2 presents estimates by race and ethnicity for the attendee sample. The same differences apply to these samples: returns are higher at the lower end of the distribution among attendees at UT-Austin and Texas A\&M. The only substantive difference comes from black UT-Austin attendees, who experience returns of over $10 \%$ below the $30^{\text {th }}$ percentile.
} 
Below the $40^{\text {th }}$ percentile, the returns for community college attendees lie above the returns for college graduates, while above the $45^{\text {th }}$ percentile the returns for community college attendees are lower than the returns for two-year graduates. However, near the top of the distribution, the returns among attendees approaches zero, with returns higher than $-5 \%$ above the $90^{\text {th }}$ percentile of the earnings distribution. The differences in these results most likely can be attributed to the fact that completion rates at community colleges are very low. ${ }^{35}$ Thus, graduates and noncompleters are likely to differ substantially with respect to future earnings, with the inclusion of community college dropouts shifting the community college earnings distribution downwards. The low completion rates at community colleges also makes the selection problem more difficult to solve among the attendee sample, as the community college dropouts are probably less similar to four-year college attendees on observable characteristics. These estimates show that for community college students there are differences in returns between graduates and attendees. While we find evidence that the returns to community college graduation may be positive for the upper part of the earnings distribution, this finding is weaker when one examines all attendees. Although the top of the attendee distribution approaches zero and the estimates become statistically indistinguishable from zero, the attendee returns approach zero higher in the distribution than in the graduate sample and never become positive. One implication of this finding is that there may be substantial returns to increasing completion rates among community college students. This issue deserves more attention in future research.

Finally, we include in our analysis all earnings for individuals who are not contemporaneously enrolled in graduate school (column (vii) in Tables 5-6 and column (v) in Table 7). In effect, this robustness check relaxes the constraint that an individual must work for three to four consecutive quarters for their earnings to be included. We do not favor this method of measuring earnings because we want to measure lifetime earnings differences as best we can with our data. Including earnings of those who may work very few hours part time or who may work part time and then leave the state or the labor market may yield a misleading picture of permanent earnings differences by school type. Using all earnings reduces the returns among UT-Austin graduates at the bottom of the distribution. Thus, we are understating the amount

\footnotetext{
${ }^{35}$ In the National Educational Longitudinal Study of 1988 (NELS:88), only $20 \%$ of community college attendees earned an AA among those who attended within two years of high school graduation. In our sample, only $14 \%$ percent of attendees who started at a community college finished with any type of degree, be it from a community college or otherwise. The analogous completion rates for UT Austin and TAMU are $77 \%$ and $82 \%$, respectively.
} 
of heterogeneity in returns by examining only full-time earnings. The Texas A\&M returns are extremely similar in column (vii) to those in column (i), and for community colleges the returns are less negative at the bottom of the distribution. However, we still find that the returns become positive at the top of the distribution for community college graduates in this sample. These estimates demonstrate that our main results and conclusions are not being driven by analyzing earnings from full-time workers only. ${ }^{36}$

\section{Conclusion}

This paper estimates quantile treatment effects of college quality on earnings using administrative data on schooling and earnings from the state of Texas. We measure quality using public college sector in Texas, examining the effects of UT-Austin, Texas A\&M and community college graduation on the distribution of earnings relative to earnings for non-flagship public four-year university graduates. While our mean estimates are consistent with previous work in this area, our quantile estimates demonstrate a large amount of heterogeneity in the earnings premium from college quality. At UT-Austin, the premia are roughly increasing with earnings, while the opposite pattern is exhibited among Texas A\&M graduates. We argue that differences in the courses of study across these schools is a potential explanation for this difference, but these results indicate that much work remains in understanding how the characteristics of a particular university map into the distribution of earnings for graduates. At community colleges, we find an overall negative effect on earnings but show that there is significant heterogeneity in the returns and uncover evidence of positive returns at the very top of the distribution.

Our data also allow us to examine returns separately by race and ethnicity, which previous work has not been able to do because of data limitations. Particularly for black and Hispanic students, who are historically under-represented in higher education in general and at highquality universities in particular, earnings premia are low for UT-Austin graduates except at the very top of the earnings distribution, but they are consistently high among Texas A\&M graduates. The returns to community college graduation is negative on average; however, for black and Hispanic community college graduates we find large and positive returns relative

\footnotetext{
${ }^{36}$ We have generated estimates using all non-graduate school earnings for the attendee sample as well, and those estimates are similarly robust to the use of this alternative earnings measure. These results are available upon request from the authors.
} 
to non-flagship public graduates of the same race and ethnicity at the top of the earnings distribution.

In drawing attention to the large amount of heterogeneity in college quality earnings premia and the differences in the quantile treatment effects across school types, this paper demonstrates the importance of considering more than the average treatment effect of college quality on earnings. Even if educational choices made by students are based on such averages, our estimates suggest that these averages mask significant uncertainty of the returns for any given student. The main policy implication of this work is that policies seeking to induce students to attend four-year universities and more selective colleges should pay attention to the distribution of returns, not simply the average, in order to target students who will benefit most from changing their attendance behavior. Future analyses that focus on identifying which students face the largest predicted returns are needed to help guide the development of such policy interventions. 


\section{References}

[1] Abadie, Alberto, Joshua Angrist and Guido Imbens, 2002. "Instrumental Variables Estimates of the Effect of Subsidized Training on the Quantiles of Trainee Earnings." Econometrica 70(1): 91-117.

[2] Angrist, Joshua, Victor Chernozhukov and Ivan Fernandez-Val, 2006. "Quantile Regression under Misspecification, with an Application to the U.S. Wage Structure." Econometrica 74(2): 539-563.

[3] Arcidiacono, Peter, 2004. "Ability Sorting and the Returns to College Major." Journal of Econometrics 121(1-2): 343-375.

[4] Arcidiacono, Peter, V. Joseph Hotz and Songman Kang, 2011. "Modeling College Major Choice using Elicited Measures of Expectations and Counterfactuals." Journal of Econometrics.

[5] Arcidiacono, Peter, Esteban M. Aucejo, Hanming Fang and Kenneth I. Spencer, 2011. "Does Affirmative Action Lead to Mismatch? A New Test and Evidence." Quantitative Economics 2(3): 303-333.

[6] Autor, David H., Laurence F. Katz and Melissa S. Kearney, 2008. "Trends in U.S. Wage Inequality: Revising the Revisionists." Review of Economics and Statistics 90(2): 300-323.

[7] Avery, Christopher and Caroline M. Hoxby, 2004. "Do and Should Financial Aid Packages Affect Students' College Choices?" In Caroline M. Hoxby (Ed.) College Choices: The Economics of Where to Go, When to Go, and How to Pay for It. Chicago: University of Chicago Press.

[8] Bitler, Marianne P., Jonah B. Gelbach and Hilary W. Hoynes, 2006. "What Mean Impacts Miss: Distributional Effects of Welfare Reform Experiments ." American Economic Review 96(4): 988-1012.

[9] Black, Dan A. and Jeffrey A. Smith, 2004. "How Robust is the Evidence on the Effects of College Quality? Evidence from Matching." Journal of Econometrics 121(1-2): 99-124.

[10] Black, Dan A. and Jeffrey A. Smith, 2006. "Estimating the Returns to College Quality with Multiple Proxies for Quality." Journal of Labor Economics 24(3): 701-728.

[11] Bound, John, Michael F. Lovenheim and Sarah Turner, 2010. "Why Have College Completion Rates Declined? An Analysis of Changing Student Preparation and Collegiate Resources." American Economic Journal: Applied Economics 2(3): 1-31.

[12] Bound, John, Michael F. Lovenheim and Sarah Turner, Forthcoming. "Increasing Time to Baccalaureate Degree in the United States." Education Finance and Policy.

[13] Brewer, Dominik, Eric Eide and Ronald Ehrenberg, 1999. "Does it Pay to Attend an Elite Private College? Cross-Cohort Evidence on the Effects of College Type on Earnings." Journal of Human Resources 34(1): 104-123.

[14] Carneiro, Pedro, Karsten T. Hansen and James J. Heckman, 2003. "Estimating Distributions of Counterfactuals with an Application to the Returns to Schooling and Measurement of the Effect of Uncertainty on Schooling Choice." International Economic Review 44(2): 361-422.

[15] Chernozhukov, Victor and Christian Hansen, 2005. "An IV Model of Quantile Treatment Effects." Econometrica 73(1): 245-261.

[16] Cortes, Kalena E., 2011. "Do Bans on Affirmative Action Hurt Minority Students? Evidence from the Texas Top 10\% Plan." Economics of Education Review 29(6): 1110-1124.

[17] Dale, Stacey Berg and Alan B. Krueger, 2011. "Estimating the Return to College Selectivity over the Career Using Administrative Earnings Data." National Bureau of Economic Research Working Paper 17159.

[18] Dale, Stacey Berg and Alan B. Krueger, 2002. "Estimating the Payoff to Attending A More Selective College: An Application of Selection on Observables and Unobservables." Quarterly Journal of Economics 117(4): 1491-1527.

[19] DiNardo, John, Nicole Fortin and Thomas Lemieux, 1996. "Labor Market Institutions and the Distribution of Wages, 1973-1992: A Semiparametric Approach." Econometrica 64(5): 1001-1044. 
[20] Doksum, Kjell, 1974. "Empirical Probability Plots and Statistical Inference for Nonlinear Models in the Two-Sample Case." The Annals of Statistics 2: 267-277.

[21] Firpo, Sergio. "Efficient Semiparametric Estimation of Quantile Treatment Effects." Econometrica 75(1): 259-276.

[22] Firpo, Sergio, Nicole Fortin and Thomas Lemieux, 2010. "Decomposition Methods in Economics" NBER Working Paper No. 16045.

[23] Flores, Carlos A. and Oscar A. Mitnik, 2009. "Evaluating Nonexperimental Estimators for Multiple Treatments: Evidence from Experimental Data ”IZA Discussion Paper No. 4451.

[24] Hoekstra, Mark, 2009. "The Effect of Attending the State Flagship University on Earnings: A DiscontinuityBased Approach." Review of Economics and Statistics 91(4): 717-724.

[25] Heckman, James J., Jeffrey Smith and Nancy Clements, 1997. "Making the Most Out of Programme Evaluations and Social Experiments: Accounting for Heterogeneity in Programme Impacts." Review of Economic Studies 64(4): 487-537.

[26] Hoxby, Caroline M., 2009. "The Changing Selectivity of American Colleges." Journal of Economic Perspectives 23(4): 95-118.

[27] Kane, Thomas J. and Cecilia Elena Rouse, 1995. "Labor-Market Returns to Two- and Four-Year College." American Economic Review 85(3): 600-614.

[28] Koenker, Roger and Gilbert Bassett Jr., 1978. "Regression Quantiles." Econometrica 46(1): 33-50.

[29] Lehmann, Erich L., 1974. Nonparametrics: Statistical Methods Based on Ranks. San Francisco: Holden-Day.

[30] Long, Bridget Terry, 2004. "How Have College Decisions Changed Over Time? An Application of the Conditional Logistic Choice Model." Journal of Econometrics 121(1-2): 271-296.

[31] Lovenheim, Michael F. and C. Lockwood Reynolds, 2011. "The Effect of Housing Wealth on College Choice: Evidence from the Housing Boom." Mimeo.

[32] Reynolds, C. Lockwood, 2009. "Where to Attend? Estimating the Effects of Beginning College at a Twoyear Institution." Mimeo.

[33] Rothstein, Jesse and Albert Yoon, 2008. "Mismatch in Law School." NBER Working Paper No. 14275.

[34] Rouse, Cecilia E., 1995. "Democratization or Diversion? The Effect of Community Colleges on Educational Attainment." Journal of Business and Economic Statistics 13(2): 217-224.

[35] Wiswal, Matthew and Basit Zafar, 2011. "Determinants of College Major Choice: Identification using an Information Experiment." Mimeo. 
Table 1: Means of Texas Public College Resource and Quality Measures by Higher Education Sector

\begin{tabular}{c|cccc}
\hline \hline & UT & Texas A\&M & Other Public & Community \\
College Station & Four-year & College \\
\hline $25^{\text {th }}$ Percentile Math SAT & 535 & 520 & 440 & \\
$75^{\text {th }}$ Percentile Math SAT & 650 & 630 & 549 & \\
Faculty-Student Ratio & 0.045 & 0.041 & 0.034 & 0.023 \\
Expenditures Per Student & 25081 & 27449 & 10981 & 5756 \\
Instructional Expenditures Per Student & 6900 & 8931 & 3648 & 2317 \\
Graduation Rate & 0.710 & 0.750 & 0.338 & \\
In-state Tuition & 3212 & 3187 & 2001 & 1217 \\
\hline \hline
\end{tabular}

${ }^{1}$ Source: 1997-2003 IPEDS data. All monetary figures are in real $\$ 2007$ and are weighted by total undergraduate enrollment. All per-student means are per total enrollment. Graduation rates are for BA degrees within six years of initial enrollment.

${ }^{2}$ SAT scores and graduation rates are reported for a small percentage of two-year schools. Because of the openadmission mandate of community colleges and the fact that many students do not intend to obtain a BA, we do not report means for SAT scores and graduation rates for these schools. 
Table 2: Summary Statistics of Analysis Variables

\begin{tabular}{|c|c|c|c|c|c|c|c|}
\hline & $\begin{array}{l}\text { UT } \\
\text { Austin } \\
\text { (i) }\end{array}$ & $\begin{array}{l}\text { Weighted } \\
\text { Non- } \\
\text { Flagship } \\
\quad \text { (ii) }\end{array}$ & $\begin{array}{l}\text { TAMU } \\
\text { College } \\
\text { Station } \\
\text { (iii) }\end{array}$ & $\begin{array}{l}\text { Weighted } \\
\text { Non- } \\
\text { Flagship } \\
\quad \text { (iv) }\end{array}$ & $\begin{array}{l}\text { Community } \\
\text { College } \\
\text { (v) }\end{array}$ & $\begin{array}{l}\text { Weighted } \\
\text { Non- } \\
\text { Flagship } \\
\quad \text { (vi) }\end{array}$ & $\begin{array}{l}\text { Un-Weighted } \\
\text { Non- } \\
\text { Flagship } \\
\text { (vii) }\end{array}$ \\
\hline Log Quarterly Earnings & $\begin{array}{c}0.167 \\
(0.657)\end{array}$ & $\begin{array}{c}0.045 \\
(0.595)\end{array}$ & $\begin{array}{c}0.248 \\
(0.546)\end{array}$ & $\begin{array}{c}0.032 \\
(0.574)\end{array}$ & $\begin{array}{l}-0.168 \\
(0.603)\end{array}$ & $\begin{array}{l}-0.075 \\
(0.564)\end{array}$ & $\begin{array}{l}-0.023 \\
(0.564)\end{array}$ \\
\hline TAAS Math Score & $\begin{array}{l}56.084 \\
(5.836)\end{array}$ & $\begin{array}{l}56.015 \\
(6.096)\end{array}$ & $\begin{array}{l}52.429 \\
(5.712)\end{array}$ & $\begin{array}{l}55.415 \\
(5.734)\end{array}$ & $\begin{array}{c}48.505 \\
(11.283)\end{array}$ & $\begin{array}{c}49.039 \\
(10.293)\end{array}$ & $\begin{array}{l}52.831 \\
(6.680)\end{array}$ \\
\hline TAAS Reading Score & $\begin{array}{l}45.022 \\
(4.304)\end{array}$ & $\begin{array}{l}44.964 \\
(4.550)\end{array}$ & $\begin{array}{l}44.623 \\
(4.381)\end{array}$ & $\begin{array}{l}44.615 \\
(4.413)\end{array}$ & $\begin{array}{l}39.670 \\
(8.950)\end{array}$ & $\begin{array}{l}40.138 \\
(8.075)\end{array}$ & $\begin{array}{l}43.031 \\
(4.978)\end{array}$ \\
\hline TAAS Writing Score & $\begin{array}{l}37.046 \\
(3.834)\end{array}$ & $\begin{array}{l}37.014 \\
(3.974)\end{array}$ & $\begin{array}{l}36.393 \\
(3.978)\end{array}$ & $\begin{array}{l}36.383 \\
(3.984)\end{array}$ & $\begin{array}{l}32.138 \\
(7.630)\end{array}$ & $\begin{array}{l}32.518 \\
(6.965)\end{array}$ & $\begin{array}{l}34.999 \\
(4.499)\end{array}$ \\
\hline Age at Graduation & $\begin{array}{l}21.829 \\
(0.934)\end{array}$ & $\begin{array}{l}22.242 \\
(1.036)\end{array}$ & $\begin{array}{l}22.098 \\
(0.860)\end{array}$ & $\begin{array}{l}22.286 \\
(1.013)\end{array}$ & $\begin{array}{l}21.304 \\
(1.743)\end{array}$ & $\begin{array}{l}22.632 \\
(1.008)\end{array}$ & $\begin{array}{c}22.438 \\
(1.0083)\end{array}$ \\
\hline $\begin{array}{l}\text { Tabulations (Percentage): } \\
\text { Math Rank }\end{array}$ & & & & & & & \\
\hline $\begin{array}{l}\text { Top } 10 \text { Percentile } \\
\text { 70th-90th Percentile } \\
\text { Below 70th Percentile }\end{array}$ & $\begin{array}{l}51.22 \\
31.33 \\
17.44\end{array}$ & $\begin{array}{l}51.31 \\
31.28 \\
17.41\end{array}$ & $\begin{array}{l}45.31 \\
33.40 \\
21.29\end{array}$ & $\begin{array}{l}45.24 \\
33.37 \\
21.39\end{array}$ & $\begin{array}{l}15.34 \\
27.24 \\
57.41\end{array}$ & $\begin{array}{l}15.68 \\
27.83 \\
56.49\end{array}$ & $\begin{array}{l}27.15 \\
32.93 \\
39.91\end{array}$ \\
\hline Reading Rank & & & & & & & \\
\hline $\begin{array}{l}\text { Top } 10 \text { Percentile } \\
\text { 70th-90th Percentile } \\
\text { Below 70th Percentile }\end{array}$ & $\begin{array}{l}43.40 \\
31.86 \\
24.74\end{array}$ & $\begin{array}{l}43.94 \\
31.49 \\
24.57\end{array}$ & $\begin{array}{l}39.21 \\
33.63 \\
27.16\end{array}$ & $\begin{array}{l}39.18 \\
33.67 \\
27.15\end{array}$ & $\begin{array}{l}13.81 \\
25.42 \\
60.77\end{array}$ & $\begin{array}{l}14.24 \\
25.95 \\
59.81\end{array}$ & $\begin{array}{l}25.16 \\
31.01 \\
43.83\end{array}$ \\
\hline Writing Rank & & & & & & & \\
\hline $\begin{array}{l}\text { Top } 10 \text { Percentile } \\
\text { 70th-90th Percentile } \\
\text { Below 70th Percentile }\end{array}$ & $\begin{array}{l}40.55 \\
32.78 \\
26.66\end{array}$ & $\begin{array}{l}41.09 \\
32.52 \\
26.39\end{array}$ & $\begin{array}{l}34.18 \\
32.88 \\
32.93\end{array}$ & $\begin{array}{l}34.14 \\
32.83 \\
33.04\end{array}$ & $\begin{array}{l}12.56 \\
23.25 \\
64.20\end{array}$ & $\begin{array}{l}13.03 \\
23.99 \\
62.98\end{array}$ & $\begin{array}{l}21.91 \\
29.72 \\
48.37\end{array}$ \\
\hline Ethnic & & & & & & & \\
\hline White & 68.82 & 67.65 & 88.59 & 88.62 & 60.68 & 61.15 & 67.03 \\
\hline Hispanic & 12.36 & 12.49 & 7.14 & 7.09 & 29.56 & 29.29 & 19.45 \\
\hline Afr. American & 2.56 & 2.60 & 1.50 & 1.49 & 6.40 & 7.00 & 8.33 \\
\hline Asian & 16.01 & 16.98 & 2.58 & 2.69 & 2.02 & 2.04 & 4.99 \\
\hline Gifted (Yes) & 42.39 & 43.36 & 32.84 & 32.99 & 7.90 & 8.21 & 18.55 \\
\hline At Risk (Yes) & 4.74 & 4.96 & 5.03 & 5.12 & 32.28 & 31.73 & 14.89 \\
\hline Not Disadvantaged & 93.77 & 93.53 & 87.08 & 96.69 & 77.05 & 77.10 & 87.08 \\
\hline Predicted Log Earnings: & & & & & & & \\
\hline Mean & 0.167 & 0.167 & 0.248 & 0.248 & -0.168 & -0.168 & \\
\hline $10^{\text {th }}$ Percentile & -0.025 & -0.019 & 0.127 & 0.127 & -0.356 & -0.352 & \\
\hline $25^{\text {th }}$ Percentile & 0.080 & 0.082 & 0.192 & 0.193 & -0.265 & -0.264 & \\
\hline $50^{\text {th }}$ Percentile & 0.184 & 0.182 & 0.257 & 0.257 & -0.143 & -0.143 & \\
\hline $75^{\text {th }}$ Percentile & 0.269 & 0.266 & 0.315 & 0.314 & -0.065 & -0.067 & \\
\hline $90^{\text {th }}$ Percentile & 0.334 & 0.329 & 0.361 & 0.360 & -0.012 & -0.015 & \\
\hline $95^{\text {th }}$ Percentile & 0.367 & 0.367 & 0.386 & 0.385 & 0.016 & 0.012 & \\
\hline Observations & 9,837 & 47,935 & 13,436 & 47,935 & 22,863 & 47,935 & 47,935 \\
\hline
\end{tabular}




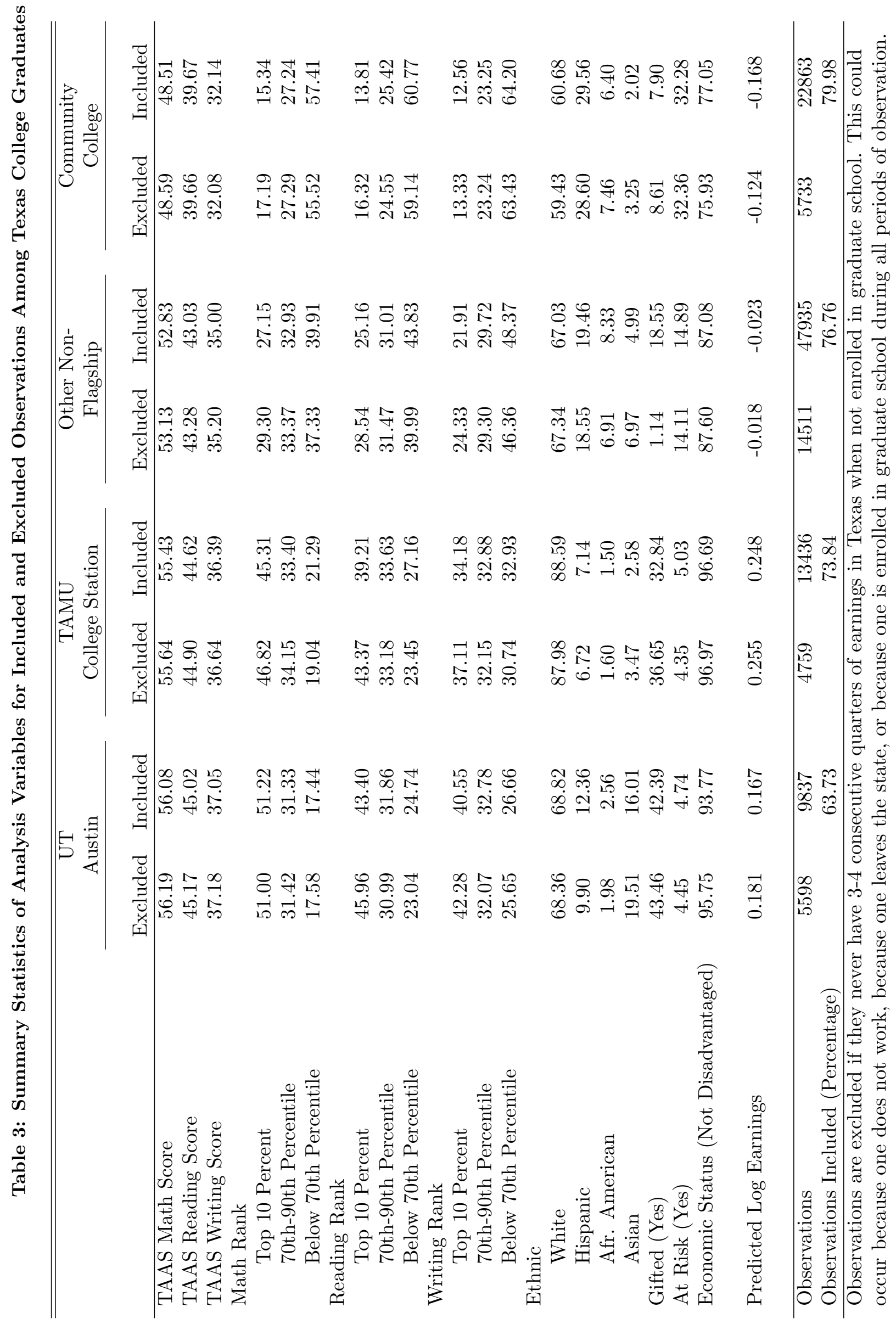


Table 4: OLS Estimates of the Effect of College Sector on Earnings

\begin{tabular}{ccll}
\hline \hline & $\begin{array}{c}\text { UT } \\
\text { Austin }\end{array}$ & $\begin{array}{c}\text { Texas A\&M } \\
\text { College Station }\end{array}$ & $\begin{array}{c}\text { Community } \\
\text { College }\end{array}$ \\
\hline No Controls: & & & \\
Full Sample & $0.190^{* *}$ & $0.272^{* *}$ & $-0.145^{* *}$ \\
& $(0.006)$ & $(0.005)$ & $(0.005)$
\end{tabular}

Test Score Controls:
Full Sample
$0.141^{* *}$
$(0.007)$
$0.237^{* *}$
$-0.106^{* *}$
$(0.005)$

Test Score, Demographic, School Experience Controls:

$\begin{array}{lccc}\text { Full Sample } & 0.128^{* *} & 0.217^{* *} & -0.099^{* *} \\ & (0.007) & (0.006) & (0.005)\end{array}$

All Controls:

$\begin{array}{cccc} & 0.115^{* *} & 0.212^{* *} & -0.100^{* *} \\ \text { Full Sample } & (0.007) & (0.006) & (0.005)\end{array}$

All Controls, By Race and Ethnicity:

\begin{tabular}{cccl}
\hline White Sample & $0.129^{* *}$ & $0.219^{* *}$ & $-0.085^{* *}$ \\
& $(0.008)$ & $(0.006)$ & $(0.006)$ \\
Black Sample & 0.034 & $0.206^{* *}$ & $-0.107^{* *}$ \\
& $(0.040)$ & $(0.043)$ & $(0.019)$ \\
Asian Sample & $0.138^{* *}$ & $0.179^{* *}$ & $-0.271^{* *}$ \\
& $(0.022)$ & $(0.034)$ & $(0.034)$ \\
Hispanic Sample & $0.035^{* *}$ & $0.180^{* *}$ & $-0.123^{* *}$ \\
& $(0.018)$ & $(0.019)$ & $(0.010)$ \\
\hline \hline
\end{tabular}

${ }^{1}$ Source: Authors' calculations from the University of Texas at Dallas Education Research Center data and administrative earnings records as described in the text. Each cell represents a separate regression, and each coefficient shows the mean adjusted earnings difference between the students graduating from each school type and the students graduating from a non-flagship public university.

2 Test score controls are quartics in the state math, reading and writing tests as well as each student's relative rank in their high school on each exam. Demographic and school experience controls include student ethnicity/race, Title I status, English proficiency, free and reduced price lunch status, enrollment in gifted programs, special education, career and technology courses, whether the student had a college plan, and whether he was at risk of dropping out. All controls add high school variables in the year of graduation: the ethnic composition of the high school, the percentage of students in each economic status group, the percentage of gifted students and students at risk, the percentage of title I eligible students, and total school enrollment.

${ }^{3}$ Robust standard errors are in parentheses: ** indicates statistical significance at the $5 \%$ level and ${ }^{*}$ indicates statistical significance at the $10 \%$ level. 
Table 5: Quantile Treatment Effects of College Sector on Earnings - UT Austin

\begin{tabular}{|c|c|c|c|c|c|c|c|}
\hline \multirow[b]{2}{*}{ Quantile } & \multirow[b]{2}{*}{$\begin{array}{l}\text { Baseline } \\
\text { (i) }\end{array}$} & \multicolumn{6}{|c|}{ Family Background Sample } \\
\hline & & $\begin{array}{l}\text { 1996-1998 } \\
\text { Cohort } \\
\text { (ii) }\end{array}$ & $\begin{array}{l}\text { HS Fixed } \\
\text { Effects } \\
\text { (iii) }\end{array}$ & $\begin{array}{l}\text { Without Back- } \\
\text { ground Variables } \\
\text { (iv) }\end{array}$ & $\begin{array}{l}\text { With Back- } \\
\text { ground Variables } \\
\text { (v) }\end{array}$ & $\begin{array}{c}\text { College } \\
\text { Attendees } \\
\quad \text { (vi) }\end{array}$ & $\begin{array}{c}\text { All } \\
\text { Earnings } \\
\text { (vii) }\end{array}$ \\
\hline \multirow[t]{2}{*}{1} & 0.120 & -0.159 & 0.117 & 0.258 & 0.258 & 0.126 & -0.320 \\
\hline & {$[-0.051,0.288]$} & {$[-0.349,0.136]$} & {$[-0.036,0.251]$} & {$[-0.070,0.476]$} & {$[-0.051,0.480]$} & {$[-0.031,0.310]$} & {$[-0.583,-0.137]$} \\
\hline \multirow[t]{2}{*}{5} & 0.049 & -0.063 & 0.075 & 0.136 & 0.162 & 0.122 & -0.099 \\
\hline & {$[-0.026,0.115]$} & {$[-0.184,0.039]$} & {$[-0.019,0.193]$} & {$[-0.002,0.294]$} & {$[0.015,0.325]$} & {$[0.052,0.193]$} & {$[-0.213,-0.006]$} \\
\hline \multirow[t]{2}{*}{10} & 0.034 & -0.042 & 0.073 & 0.067 & 0.081 & 0.115 & -0.050 \\
\hline & {$[-0.013,0.075]$} & {$[-0.099,0.008]$} & {$[0.017,0.137]$} & {$[-0.026,0.158]$} & {$[-0.016,0.172]$} & {$[0.070,0.162]$} & {$[-0.112,0.013]$} \\
\hline \multirow[t]{2}{*}{15} & 0.037 & -0.004 & 0.077 & 0.071 & 0.083 & 0.100 & -0.023 \\
\hline & {$[0.007,0.075]$} & {$[-0.040,0.041]$} & {$[0.039,0.115]$} & {$[0.014,0.125]$} & {$[0.019,0.133]$} & {$[0.073,0.139]$} & {$[-0.083,0.029]$} \\
\hline \multirow[t]{2}{*}{20} & 0.047 & 0.018 & 0.085 & 0.068 & 0.083 & 0.109 & 0.008 \\
\hline & {$[0.023,0.074]$} & {$[-0.018,0.051]$} & {$[0.054,0.119]$} & {$[0.018,0.118]$} & {$[0.036,0.135]$} & {$[0.086,0.142]$} & {$[-0.028,0.048]$} \\
\hline \multirow[t]{2}{*}{25} & 0.063 & 0.039 & 0.099 & 0.096 & 0.109 & 0.114 & 0.016 \\
\hline & {$[0.038,0.087]$} & {$[0.006,0.066]$} & {$[0.063,0.126]$} & {$[0.050,0.130]$} & {$[0.060,0.145]$} & {$[0.092,0.140]$} & {$[-0.020,0.052]$} \\
\hline \multirow[t]{2}{*}{30} & 0.074 & 0.056 & 0.100 & 0.087 & 0.097 & 0.113 & 0.027 \\
\hline & {$[0.056,0.091]$} & {$[0.031,0.074]$} & {$[0.071,0.121]$} & {$[0.063,0.116]$} & {$[0.067,0.130]$} & {$[0.096,0.136]$} & {$[-0.009,0.059]$} \\
\hline \multirow[t]{2}{*}{35} & 0.080 & 0.063 & 0.097 & 0.088 & 0.097 & 0.108 & 0.044 \\
\hline & {$[0.060,0.097]$} & {$[0.037,0.084]$} & {$[0.074,0.117]$} & {$[0.063,0.117]$} & {$[0.064,0.123]$} & {$[0.089,0.127]$} & {$[0.012,0.064]$} \\
\hline \multirow[t]{2}{*}{40} & 0.092 & 0.078 & 0.107 & 0.090 & 0.095 & 0.115 & 0.050 \\
\hline & {$[0.074,0.110]$} & {$[0.057,0.110]$} & {$[0.085,0.127]$} & {$[0.060,0.119]$} & {$[0.067,0.124]$} & {$[0.096,0.139]$} & {$[0.023,0.071]$} \\
\hline \multirow[t]{2}{*}{45} & 0.108 & 0.120 & 0.126 & 0.100 & 0.102 & 0.135 & 0.074 \\
\hline & {$[0.092,0.125]$} & {$[0.090,0.151]$} & {$[0.105,0.145]$} & {$[0.072,0.122]$} & {$[0.072,0.125]$} & {$[0.117,0.156]$} & {$[0.050,0.092]$} \\
\hline \multirow[t]{2}{*}{50} & 0.121 & 0.149 & 0.144 & 0.102 & 0.105 & 0.146 & 0.087 \\
\hline & {$[0.102,0.141]$} & {$[0.115,0.175]$} & {$[0.121,0.163]$} & {$[0.074,0.131]$} & {$[0.075,0.136]$} & {$[0.127,0.163]$} & {$[0.066,0.103]$} \\
\hline \multirow[t]{2}{*}{55} & 0.135 & 0.164 & 0.157 & 0.125 & 0.127 & 0.154 & 0.096 \\
\hline & {$[0.118,0.155]$} & {$[0.135,0.189]$} & {$[0.135,0.173]$} & {$[0.096,0.151]$} & {$[0.100,0.154]$} & {$[0.139,0.174]$} & {$[0.078,0.115]$} \\
\hline \multirow[t]{2}{*}{60} & 0.150 & 0.178 & 0.170 & 0.136 & 0.139 & 0.166 & 0.116 \\
\hline & {$[0.134,0.167]$} & {$[0.154,0.200]$} & {$[0.147,0.191]$} & {$[0.109,0.162]$} & {$[0.111,0.165]$} & {$[0.152,0.181]$} & {$[0.095,0.135]$} \\
\hline \multirow[t]{2}{*}{65} & 0.162 & 0.179 & 0.178 & 0.132 & 0.132 & 0.169 & 0.123 \\
\hline & {$[0.142,0.177]$} & {$[0.157,0.209]$} & {$[0.154,0.197]$} & {$[0.111,0.159]$} & {$[0.112,0.161]$} & {$[0.152,0.185]$} & {$[0.105,0.138]$} \\
\hline \multirow[t]{2}{*}{70} & 0.164 & 0.186 & 0.177 & 0.141 & 0.139 & 0.170 & 0.135 \\
\hline & {$[0.145,0.177]$} & {$[0.155,0.215]$} & {$[0.154,0.195]$} & {$[0.122,0.162]$} & {$[0.115,0.165]$} & {$[0.156,0.187]$} & {$[0.114,0.154]$} \\
\hline \multirow[t]{2}{*}{75} & 0.168 & 0.188 & 0.171 & 0.145 & 0.141 & 0.174 & 0.147 \\
\hline & {$[0.152,0.179]$} & {$[0.163,0.213]$} & {$[0.148,0.193]$} & {$[0.128,0.168]$} & {$[0.122,0.162]$} & {$[0.160,0.190]$} & {$[0.128,0.167]$} \\
\hline \multirow[t]{2}{*}{80} & 0.165 & 0.190 & 0.175 & 0.156 & 0.153 & 0.168 & 0.156 \\
\hline & {$[0.147,0.184]$} & {$[0.162,0.217]$} & {$[0.149,0.198]$} & {$[0.140,0.178]$} & {$[0.134,0.174]$} & {$[0.154,0.186]$} & {$[0.135,0.172]$} \\
\hline \multirow[t]{2}{*}{85} & 0.176 & 0.201 & 0.186 & 0.168 & 0.166 & 0.173 & 0.161 \\
\hline & {$[0.159,0.196]$} & {$[0.167,0.229]$} & {$[0.166,0.202]$} & {$[0.148,0.189]$} & {$[0.142,0.186]$} & {$[0.157,0.191]$} & {$[0.140,0.177]$} \\
\hline \multirow[t]{2}{*}{90} & 0.189 & 0.229 & 0.194 & 0.186 & 0.181 & 0.181 & 0.175 \\
\hline & {$[0.173,0.217]$} & {$[0.187,0.268]$} & {$[0.162,0.226]$} & {$[0.155,0.219]$} & {$[0.150,0.217]$} & {$[0.161,0.204]$} & {$[0.154,0.197]$} \\
\hline \multirow[t]{2}{*}{95} & 0.280 & 0.336 & 0.278 & 0.257 & 0.255 & 0.247 & 0.221 \\
\hline & {$[0.244,0.313]$} & {$[0.273,0.386]$} & {$[0.236,0.314]$} & {$[0.197,0.304]$} & {$[0.185,0.299]$} & {$[0.210,0.283]$} & {$[0.182,0.247]$} \\
\hline 99 & 0.278 & 0.191 & 0.302 & 0.326 & 0.337 & 0.238 & 0.236 \\
\hline & {$[0.208,0.326]$} & {$[0.058,0.332]$} & {$[0.258,0.357]$} & {$[0.269,0.409]$} & {$[0.270,0.415]$} & {$[0.135,0.287]$} & {$[0.173,0.288]$} \\
\hline
\end{tabular}

The table shows quantile treatment effect estimates with the bounds of bootstrapped $95 \%$ confidence intervals in brackets. All models control for quartics in the state math, reading and writing tests as well as each student's relative rank in their high school on each exam, student ethnicity/race, Title I status, English proficiency, free and reduced price lunch status, enrollment in gifted programs, special education, career and technology courses, whether the student had a college plan, and whether he was at risk of dropping out. The estimates also control for high school characteristics in the year of graduation: the ethnic composition of the high school, the percentage of students in each economic status group, the percentage of gifted students and students at risk, the percentage of title I eligible students, and total school enrollment. 
Table 6: Quantile Treatment Effects of College Sector on Earnings - Texas A\&M

\begin{tabular}{|c|c|c|c|c|c|c|c|}
\hline \multirow[b]{2}{*}{ Quantile } & \multirow[b]{2}{*}{$\begin{array}{l}\text { Baseline } \\
\text { (i) }\end{array}$} & \multicolumn{6}{|c|}{ Family Background Sample } \\
\hline & & $\begin{array}{l}\text { 1996-1998 } \\
\text { Cohort } \\
\text { (ii) }\end{array}$ & $\begin{array}{l}\text { HS Fixed } \\
\text { Effects } \\
\text { (iii) }\end{array}$ & $\begin{array}{l}\text { Without Back- } \\
\text { ground Variables } \\
\text { (iv) }\end{array}$ & $\begin{array}{c}\text { With Back- } \\
\text { ground Variables } \\
(\mathrm{v})\end{array}$ & $\begin{array}{l}\text { College } \\
\text { Attendees } \\
\quad \text { (vi) }\end{array}$ & $\begin{array}{c}\text { All } \\
\text { Earnings } \\
\text { (vii) }\end{array}$ \\
\hline \multirow[t]{2}{*}{1} & 0.364 & 0.422 & 0.315 & 0.360 & 0.367 & 0.398 & 0.101 \\
\hline & {$[0.254,0.499]$} & {$[0.234,0.642]$} & {$[0.214,0.452]$} & {$[0.143,0.505]$} & {$[0.154,0.515]$} & {$[0.299,0.516]$} & {$[-0.120,0.346]$} \\
\hline \multirow[t]{2}{*}{5} & 0.314 & 0.242 & 0.300 & 0.341 & 0.341 & 0.370 & 0.300 \\
\hline & {$[0.267,0.345]$} & {$[0.185,0.306]$} & {$[0.250,0.368]$} & {$[0.262,0.411]$} & {$[0.262,0.415]$} & {$[0.319,0.413]$} & {$[0.210,0.382]$} \\
\hline \multirow[t]{2}{*}{10} & 0.279 & 0.231 & 0.285 & 0.314 & 0.310 & 0.359 & 0.295 \\
\hline & {$[0.253,0.304]$} & {$[0.203,0.265]$} & {$[0.253,0.325]$} & {$[0.256,0.363]$} & {$[0.251,0.357]$} & {$[0.328,0.394]$} & {$[0.240,0.351]$} \\
\hline \multirow[t]{2}{*}{15} & 0.247 & 0.200 & 0.254 & 0.292 & 0.291 & 0.320 & 0.300 \\
\hline & {$[0.226,0.267]$} & {$[0.172,0.225]$} & {$[0.229,0.277]$} & {$[0.245,0.318]$} & {$[0.244,0.317]$} & {$[0.299,0.340]$} & {$[0.257,0.332]$} \\
\hline \multirow[t]{2}{*}{20} & 0.214 & 0.178 & 0.227 & 0.253 & 0.253 & 0.292 & 0.271 \\
\hline & {$[0.201,0.231]$} & {$[0.153,0.199]$} & {$[0.211,0.246]$} & {$[0.228,0.279]$} & {$[0.228,0.278]$} & {$[0.276,0.311]$} & {$[0.250,0.292]$} \\
\hline \multirow[t]{2}{*}{25} & 0.205 & 0.171 & 0.211 & 0.238 & 0.238 & 0.264 & 0.251 \\
\hline & {$[0.192,0.219]$} & {$[0.151,0.187]$} & {$[0.197,0.227]$} & {$[0.214,0.265]$} & {$[0.214,0.265]$} & {$[0.251,0.283]$} & {$[0.234,0.269]$} \\
\hline \multirow[t]{2}{*}{30} & 0.208 & 0.181 & 0.209 & 0.226 & 0.225 & 0.252 & 0.225 \\
\hline & {$[0.196,0.220]$} & {$[0.162,0.197]$} & {$[0.195,0.224]$} & {$[0.205,0.251]$} & {$[0.204,0.250]$} & {$[0.241,0.266]$} & {$[0.211,0.243]$} \\
\hline \multirow[t]{2}{*}{35} & 0.209 & 0.191 & 0.212 & 0.222 & 0.221 & 0.247 & 0.220 \\
\hline & {$[0.199,0.222]$} & {$[0.176,0.205]$} & {$[0.202,0.227]$} & {$[0.203,0.238]$} & {$[0.202,0.238]$} & {$[0.235,0.260]$} & {$[0.206,0.233]$} \\
\hline \multirow[t]{2}{*}{40} & 0.213 & 0.207 & 0.215 & 0.212 & 0.211 & 0.243 & 0.218 \\
\hline & {$[0.202,0.225]$} & {$[0.190,0.220]$} & {$[0.203,0.230]$} & {$[0.196,0.231]$} & {$[0.194,0.230]$} & {$[0.231,0.254]$} & {$[0.205,0.231]$} \\
\hline \multirow[t]{2}{*}{45} & 0.215 & 0.221 & 0.223 & 0.211 & 0.209 & 0.243 & 0.221 \\
\hline & {$[0.202,0.225]$} & {$[0.206,0.237]$} & {$[0.210,0.239]$} & {$[0.194,0.228]$} & {$[0.192,0.227]$} & {$[0.232,0.258]$} & {$[0.211,0.235]$} \\
\hline \multirow[t]{2}{*}{50} & 0.218 & 0.229 & 0.228 & 0.213 & 0.211 & 0.244 & 0.223 \\
\hline & {$[0.207,0.228]$} & {$[0.215,0.246]$} & {$[0.217,0.241]$} & {$[0.199,0.227]$} & {$[0.195,0.226]$} & {$[0.234,0.257]$} & {$[0.209,0.234]$} \\
\hline \multirow[t]{2}{*}{55} & 0.215 & 0.231 & 0.223 & 0.207 & 0.205 & 0.240 & 0.221 \\
\hline & {$[0.206,0.224]$} & {$[0.216,0.247]$} & {$[0.213,0.237]$} & {$[0.192,0.221]$} & {$[0.189,0.219]$} & {$[0.231,0.250]$} & {$[0.208,0.233]$} \\
\hline \multirow[t]{2}{*}{60} & 0.211 & 0.226 & 0.223 & 0.209 & 0.206 & 0.232 & 0.218 \\
\hline & {$[0.200,0.221]$} & {$[0.209,0.241]$} & {$[0.213,0.237]$} & {$[0.192,0.223]$} & {$[0.190,0.221]$} & {$[0.221,0.244]$} & {$[0.206,0.229]$} \\
\hline \multirow[t]{2}{*}{65} & 0.206 & 0.219 & 0.218 & 0.196 & 0.193 & 0.226 & 0.212 \\
\hline & {$[0.196,0.217]$} & {$[0.203,0.233]$} & {$[0.209,0.231]$} & {$[0.182,0.213]$} & {$[0.180,0.209]$} & {$[0.216,0.237]$} & {$[0.200,0.229]$} \\
\hline \multirow[t]{2}{*}{70} & 0.194 & 0.208 & 0.210 & 0.189 & 0.186 & 0.210 & 0.203 \\
\hline & {$[0.183,0.204]$} & {$[0.190,0.224]$} & {$[0.200,0.221]$} & {$[0.175,0.204]$} & {$[0.173,0.202]$} & {$[0.201,0.220]$} & {$[0.192,0.213]$} \\
\hline \multirow[t]{2}{*}{75} & 0.187 & 0.195 & 0.203 & 0.182 & 0.178 & 0.197 & 0.191 \\
\hline & {$[0.175,0.196]$} & {$[0.178,0.211]$} & {$[0.192,0.213]$} & {$[0.166,0.195]$} & {$[0.162,0.193]$} & {$[0.188,0.206]$} & {$[0.180,0.202]$} \\
\hline \multirow[t]{2}{*}{80} & 0.181 & 0.187 & 0.195 & 0.176 & 0.172 & 0.193 & 0.184 \\
\hline & {$[0.172,0.192]$} & {$[0.167,0.205]$} & {$[0.183,0.205]$} & {$[0.162,0.191]$} & {$[0.158,0.188]$} & {$[0.182,0.204]$} & {$[0.174,0.197]$} \\
\hline \multirow[t]{2}{*}{85} & 0.177 & 0.186 & 0.189 & 0.175 & 0.170 & 0.184 & 0.186 \\
\hline & {$[0.166,0.190]$} & {$[0.161,0.205]$} & {$[0.176,0.202]$} & {$[0.154,0.190]$} & {$[0.150,0.187]$} & {$[0.175,0.198]$} & {$[0.173,0.201]$} \\
\hline \multirow[t]{2}{*}{90} & 0.178 & 0.191 & 0.187 & 0.166 & 0.163 & 0.176 & 0.180 \\
\hline & {$[0.163,0.194]$} & {$[0.166,0.213]$} & {$[0.169,0.202]$} & {$[0.146,0.186]$} & {$[0.141,0.183]$} & {$[0.161,0.191]$} & {$[0.165,0.196]$} \\
\hline \multirow[t]{2}{*}{95} & 0.201 & 0.234 & 0.207 & 0.165 & 0.163 & 0.198 & 0.185 \\
\hline & {$[0.180,0.224]$} & {$[0.194,0.265]$} & {$[0.182,0.235]$} & {$[0.140,0.201]$} & {$[0.136,0.198]$} & {$[0.175,0.223]$} & {$[0.170,0.202]$} \\
\hline 99 & 0.192 & 0.173 & 0.206 & 0.184 & 0.182 & 0.170 & 0.182 \\
\hline & {$[0.152,0.240]$} & {$[0.086,0.258]$} & {$[0.166,0.255]$} & {$[0.134,0.247]$} & {$[0.134,0.241]$} & {$[0.138,0.206]$} & {$[0.143,0.228]$} \\
\hline
\end{tabular}

The table shows quantile treatment effect estimates with the bounds of bootstrapped $95 \%$ confidence intervals in brackets. All models control for quartics in the state math, reading and writing tests as well as each student's relative rank in their high school on each exam, student ethnicity/race, Title I status, English proficiency, free and reduced price lunch status, enrollment in gifted programs, special education, career and technology courses, whether the student had a college plan, and whether he was at risk of dropping out. The estimates also control for high school characteristics in the year of graduation: the ethnic composition of the high school, the percentage of students in each economic status group, the percentage of gifted students and students at risk, the percentage of title I eligible students, and total school enrollment. 
Table 7: Quantile Treatment Effects of College Sector on Earnings - Community College

\begin{tabular}{|c|c|c|c|c|c|}
\hline Quantile & $\begin{array}{l}\text { Baseline } \\
\text { (i) }\end{array}$ & $\begin{array}{c}1996-1998 \\
\text { Cohort } \\
\text { (ii) }\end{array}$ & $\begin{array}{l}\text { HS Fixed } \\
\text { Effects } \\
\text { (iii) }\end{array}$ & $\begin{array}{c}\text { College } \\
\text { Attendees } \\
\text { (iv) }\end{array}$ & $\begin{array}{c}\text { All } \\
\text { Earnings } \\
(\mathrm{v})\end{array}$ \\
\hline \multirow[t]{2}{*}{1} & -0.098 & -0.291 & -0.113 & -0.076 & 0.142 \\
\hline & {$[-0.203,0.055]$} & {$[-0.455,-0.114]$} & {$[-0.228,0.120]$} & {$[-0.192,0.035]$} & {$[-0.089,0.319]$} \\
\hline \multirow[t]{2}{*}{5} & -0.132 & -0.194 & -0.130 & -0.061 & -0.092 \\
\hline & {$[-0.192,-0.090]$} & {$[-0.307,-0.106]$} & {$[-0.180,-0.068]$} & {$[-0.109,-0.032]$} & {$[-0.158,-0.011]$} \\
\hline \multirow[t]{2}{*}{10} & -0.193 & -0.223 & -0.197 & -0.099 & -0.095 \\
\hline & {$[-0.226,-0.162]$} & {$[-0.288,-0.139]$} & {$[-0.233,-0.155]$} & {$[-0.125,-0.064]$} & {$[-0.138,-0.054]$} \\
\hline \multirow[t]{2}{*}{15} & -0.207 & -0.232 & -0.206 & -0.121 & -0.140 \\
\hline & {$[-0.229,-0.185]$} & {$[-0.263,-0.182]$} & {$[-0.233,-0.181]$} & {$[-0.141,-0.101]$} & {$[-0.173,-0.108]$} \\
\hline \multirow[t]{2}{*}{20} & -0.197 & -0.206 & -0.205 & -0.123 & -0.147 \\
\hline & {$[-0.216,-0.174]$} & {$[-0.227,-0.168]$} & {$[-0.222,-0.182]$} & {$[-0.145,-0.098]$} & {$[-0.179,-0.124]$} \\
\hline \multirow[t]{2}{*}{25} & -0.177 & -0.177 & -0.185 & -0.129 & -0.153 \\
\hline & {$[-0.198,-0.160]$} & {$[-0.202,-0.147]$} & {$[-0.200,-0.164]$} & {$[-0.146,-0.096]$} & {$[-0.174,-0.129]$} \\
\hline \multirow[t]{2}{*}{30} & -0.156 & -0.150 & -0.165 & -0.126 & -0.133 \\
\hline & {$[-0.174,-0.144]$} & {$[-0.170,-0.127]$} & {$[-0.177,-0.148]$} & {$[-0.142,-0.101]$} & {$[-0.153,-0.118]$} \\
\hline \multirow[t]{2}{*}{35} & -0.136 & -0.129 & -0.141 & -0.124 & -0.123 \\
\hline & {$[-0.151,-0.124]$} & {$[-0.147,-0.106]$} & {$[-0.155,-0.124]$} & {$[-0.138,-0.108]$} & {$[-0.138,-0.107]$} \\
\hline \multirow[t]{2}{*}{40} & -0.120 & -0.112 & -0.128 & -0.119 & -0.106 \\
\hline & {$[-0.133,-0.107]$} & {$[-0.127,-0.091]$} & {$[-0.140,-0.113]$} & {$[-0.130,-0.101]$} & {$[-0.120,-0.089]$} \\
\hline \multirow[t]{2}{*}{45} & -0.101 & -0.092 & -0.112 & -0.115 & -0.092 \\
\hline & {$[-0.114,-0.091]$} & {$[-0.112,-0.070]$} & {$[-0.127,-0.100]$} & {$[-0.125,-0.099]$} & {$[-0.105,-0.079]$} \\
\hline \multirow[t]{2}{*}{50} & -0.086 & -0.064 & -0.092 & -0.113 & -0.075 \\
\hline & {$[-0.095,-0.075]$} & {$[-0.082,-0.045]$} & {$[-0.104,-0.081]$} & {$[-0.123,-0.099]$} & {$[-0.086,-0.061]$} \\
\hline \multirow[t]{2}{*}{55} & -0.072 & -0.047 & -0.076 & -0.104 & -0.061 \\
\hline & {$[-0.082,-0.059]$} & {$[-0.062,-0.026]$} & {$[-0.090,-0.063]$} & {$[-0.112,-0.092]$} & {$[-0.073,-0.049]$} \\
\hline \multirow[t]{2}{*}{60} & -0.059 & -0.036 & -0.064 & -0.095 & -0.049 \\
\hline & {$[-0.070,-0.047]$} & {$[-0.051,-0.018]$} & {$[-0.076,-0.053]$} & {$[-0.104,-0.085]$} & {$[-0.060,-0.037]$} \\
\hline \multirow[t]{2}{*}{65} & -0.048 & -0.022 & -0.050 & -0.086 & -0.036 \\
\hline & {$[-0.059,-0.036]$} & {$[-0.039,-0.003]$} & {$[-0.064,-0.037]$} & {$[-0.096,-0.075]$} & {$[-0.047,-0.027]$} \\
\hline \multirow[t]{2}{*}{70} & -0.037 & -0.014 & -0.039 & -0.078 & -0.023 \\
\hline & {$[-0.049,-0.025]$} & {$[-0.030,0.008]$} & {$[-0.053,-0.024]$} & {$[-0.090,-0.068]$} & {$[-0.035,-0.014]$} \\
\hline \multirow[t]{2}{*}{75} & -0.030 & -0.016 & -0.028 & -0.072 & -0.017 \\
\hline & {$[-0.043,-0.018]$} & {$[-0.034,0.007]$} & {$[-0.041,-0.016]$} & {$[-0.082,-0.062]$} & {$[-0.029,-0.004$} \\
\hline \multirow[t]{2}{*}{80} & -0.019 & -0.019 & -0.020 & -0.068 & -0.005 \\
\hline & {$[-0.032,-0.008]$} & {$[-0.037,0.002]$} & {$[-0.036,-0.007]$} & {$[-0.077,-0.058]$} & {$[-0.017,0.006]$} \\
\hline \multirow[t]{2}{*}{85} & -0.014 & -0.030 & -0.017 & -0.058 & 0.004 \\
\hline & {$[-0.026,0.000]$} & {$[-0.049,-0.007]$} & {$[-0.032,-0.003]$} & {$[-0.068,-0.049]$} & {$[-0.009,0.017]$} \\
\hline \multirow[t]{2}{*}{90} & -0.008 & -0.038 & -0.011 & -0.050 & 0.015 \\
\hline & {$[-0.019,0.004]$} & {$[-0.062,-0.008]$} & {$[-0.028,0.001]$} & {$[-0.060,-0.038]$} & {$[0.001,0.027]$} \\
\hline \multirow[t]{2}{*}{95} & 0.015 & -0.039 & 0.012 & -0.038 & 0.034 \\
\hline & {$[0.002,0.029]$} & {$[-0.063,-0.013]$} & {$[-0.006,0.030]$} & {$[-0.051,-0.025]$} & {$[0.015,0.051]$} \\
\hline \multirow[t]{2}{*}{99} & -0.040 & -0.212 & -0.043 & -0.045 & 0.011 \\
\hline & {$[-0.070,-0.004]$} & {$[-0.289,-0.138]$} & {$[-0.080,-0.008]$} & {$[-0.072,-0.013]$} & {$[-0.024,0.044]$} \\
\hline
\end{tabular}

The table shows the quantile treatment effects for each school type with the bounds of the $95 \%$ confidence intervals that are calculated using 250 bootstrap replications in brackets. The table shows quantile treatment effect estimates with the bounds of bootstrapped the $95 \%$ confidence intervals in brackets. All models control for quartics in the state math, reading and writing tests as well as each student's relative rank in their high school on each exam, student ethnicity/race, Title I status, English proficiency, free and reduced price lunch status, enrollment in gifted programs, special education, career and technology courses, whether the student had a college plan, and whether he was at risk of dropping out. The estimates also control for high school characteristics in the year of graduation: the ethnic composition of the high school, the percentage of students in each economic status group, the percentage of gifted students and students at risk, the percentage of title I eligible students, and total school enrollment. 
Table 8: Average Residual Log Earnings by Major from Male College Graduates in Texas

\begin{tabular}{lcc}
\hline \hline Major & Mean & Std. Deviation \\
\hline Agriculture & 0.008 & 0.514 \\
Liberal Arts & -0.293 & 0.642 \\
Social Science & -0.105 & 0.622 \\
Communication & -0.242 & 0.632 \\
Math/Computer Science & 0.091 & 0.569 \\
Science & -0.020 & 0.650 \\
Business & 0.112 & 0.545 \\
Engineering & 0.234 & 0.529 \\
\hline \hline
\end{tabular}

The table shows the mean and standard deviation of residualized log earnings among male college graduates from all schools in Texas. The log wage residuals are the same as those used to generate the quantile treatment effects. 
Figure 1: Distribution of Log Earnings in the 2000 Census Among BA Recipients of College Age 5 Years Prior by Location of Residence 5 Years Prior and by State of Current Residence

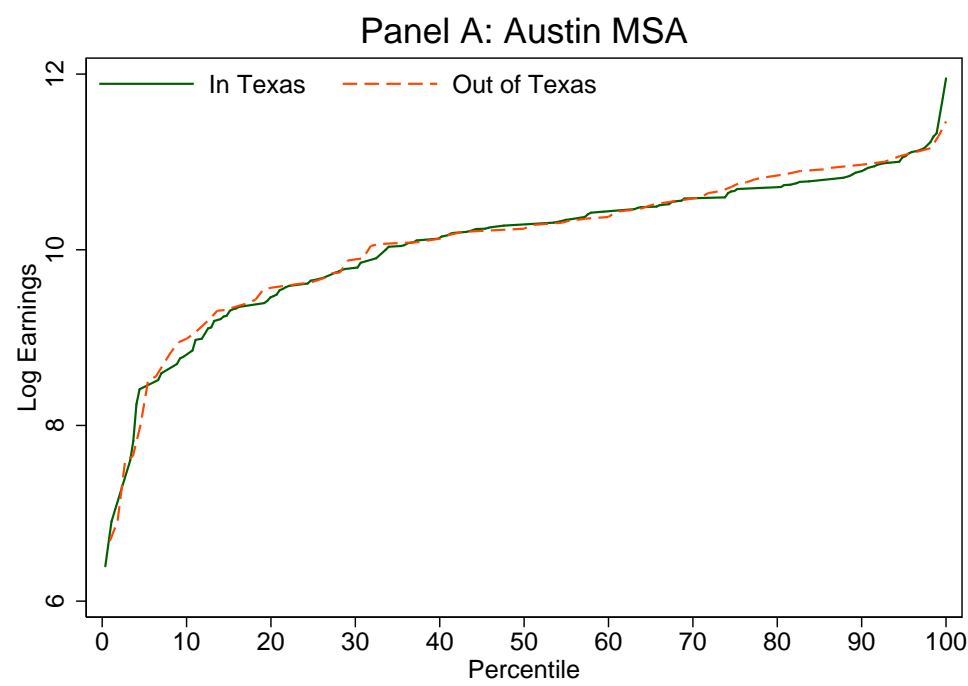

Panel B: College Station MSA

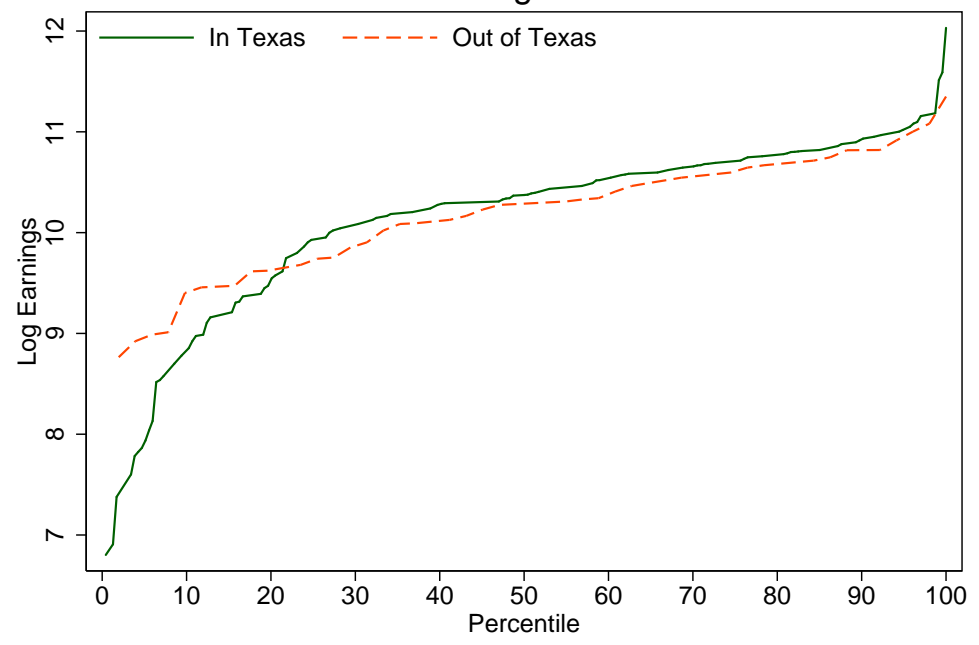

Panel C: All Other Areas of Texas

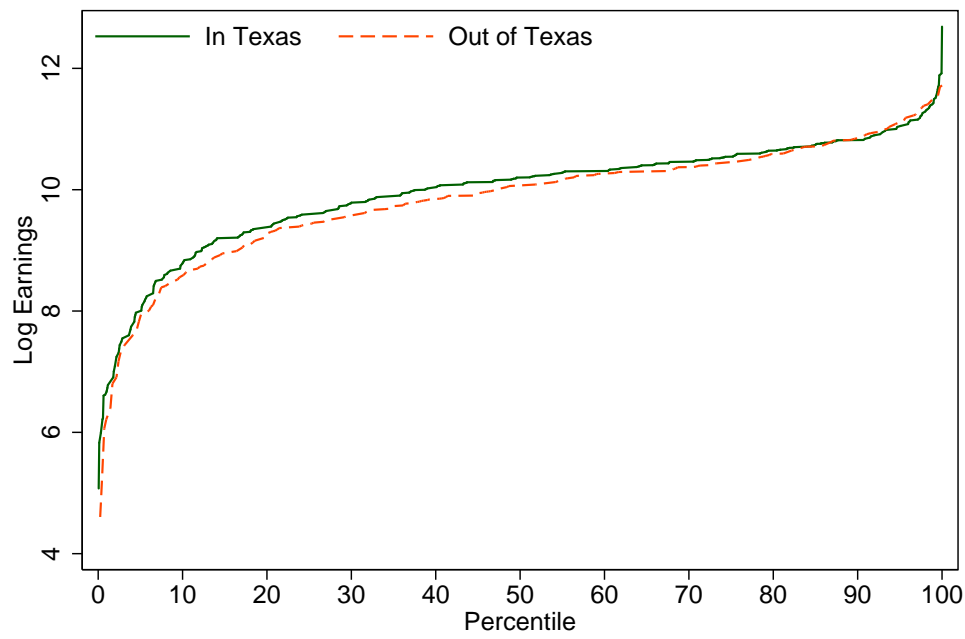

Each panel shows log earnings distributions for respondents 23-26 years old with a BA in the 2000 Census who reported living in the Austin MSA (Panel A), the College Station MSA (Panel B) or in any other part of Texas (Panel C) in 1995. Among those who reported living in each area in 1995, the figures show log earnings distributions by whether the respondent lives in Texas in 2000 or not. 
Figure 2: Distribution of Propensity Scores Among Treated and Control Observations by School Treatment Type
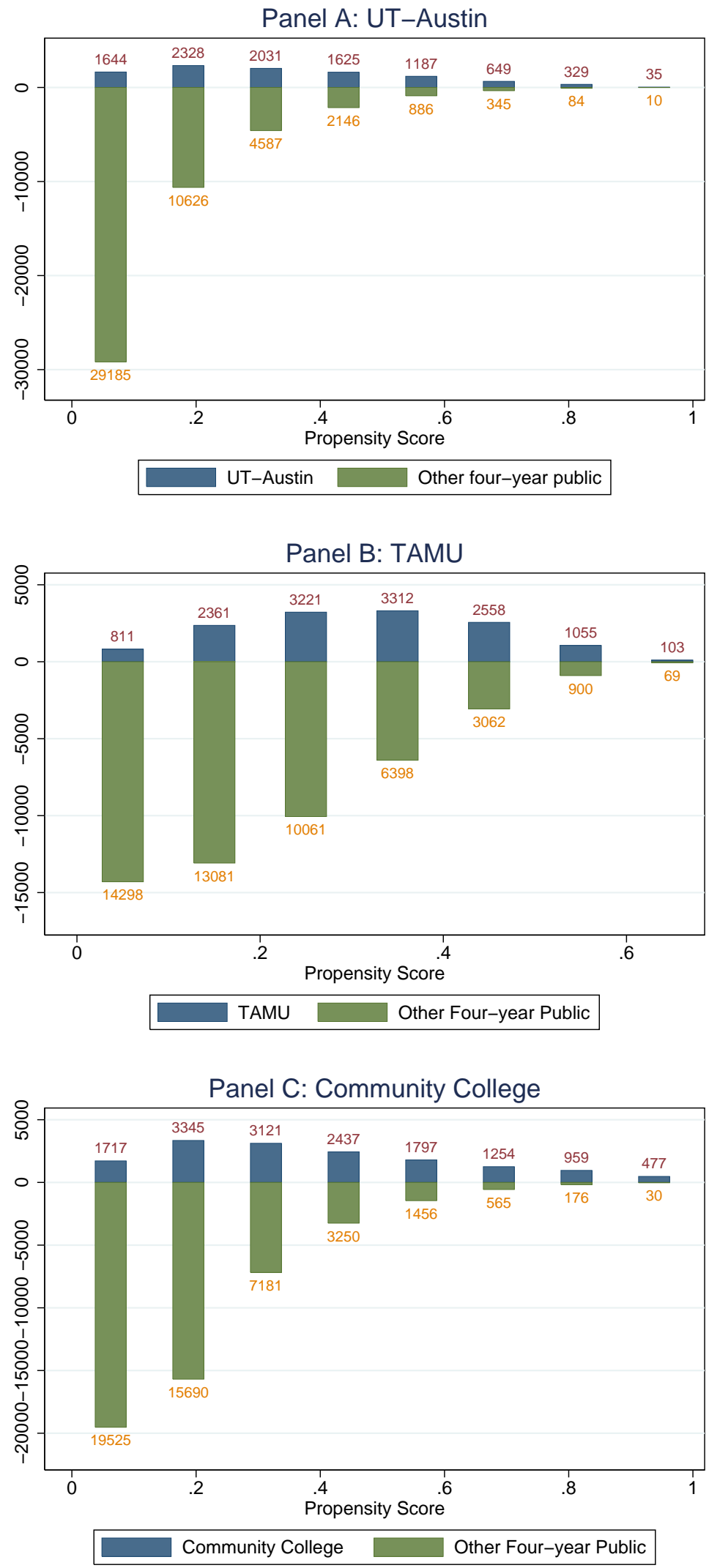

Each panel shows propensity score distributions from estimation of equation (8) in the text for each treatment school type and non-flagship universities. Each set of bars show the estimated probability of graduating from the treatment school relative to non-flagship schools, separately by the type of school from which the individual actually graduated. The range of the bars in each panel are constrained by the confidentiality agreement we signed for data use that restricts any reported results to be based on 10 or more observations. 
Figure 3: Observed and Counterfactual Earnings Distributions, by School Type

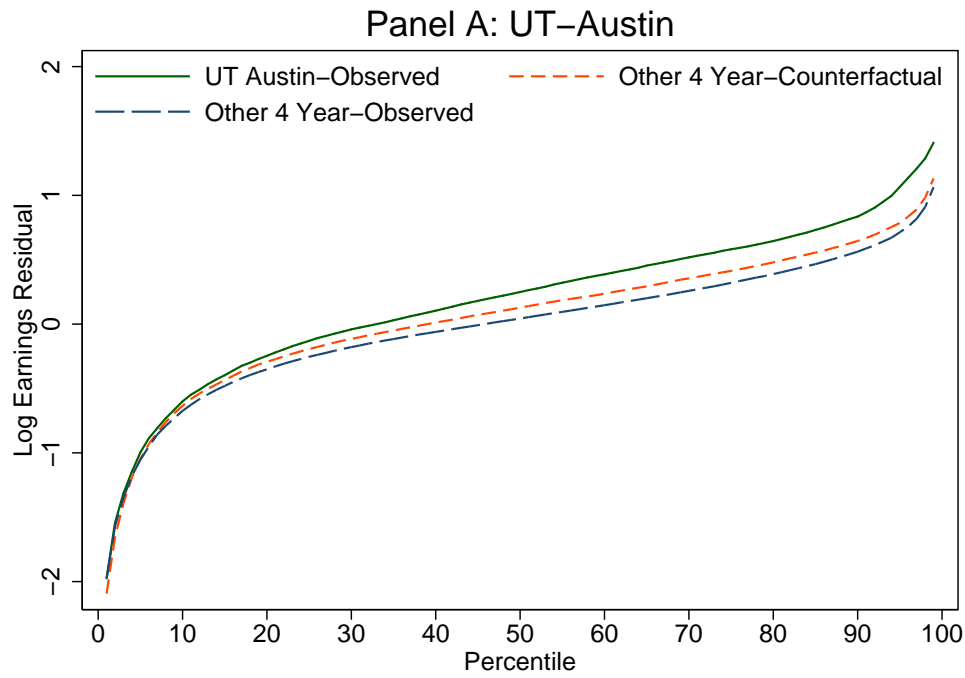

\section{Panel B: Texas A\&M}

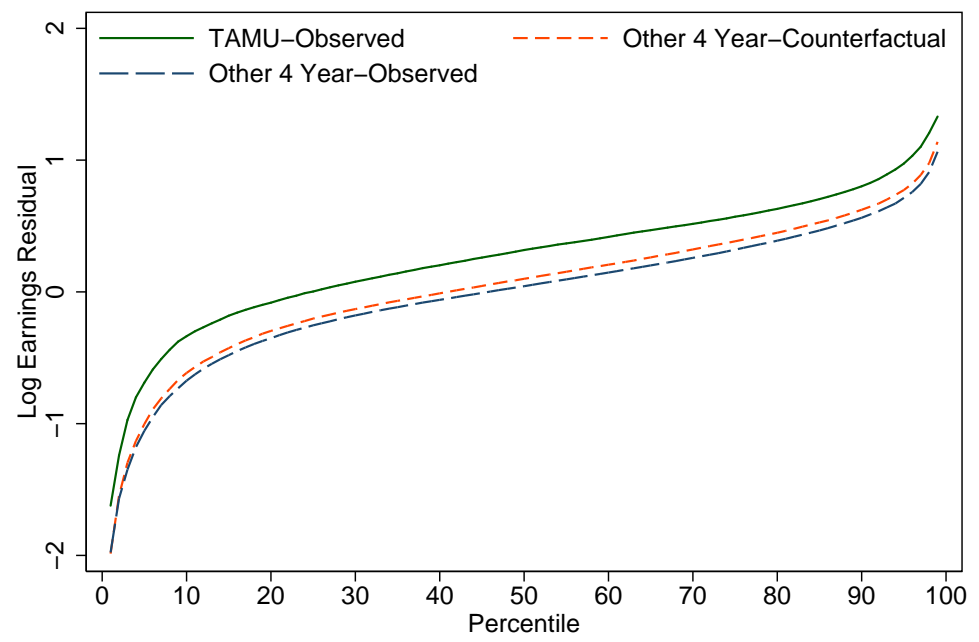

Panel C: Community Colleges

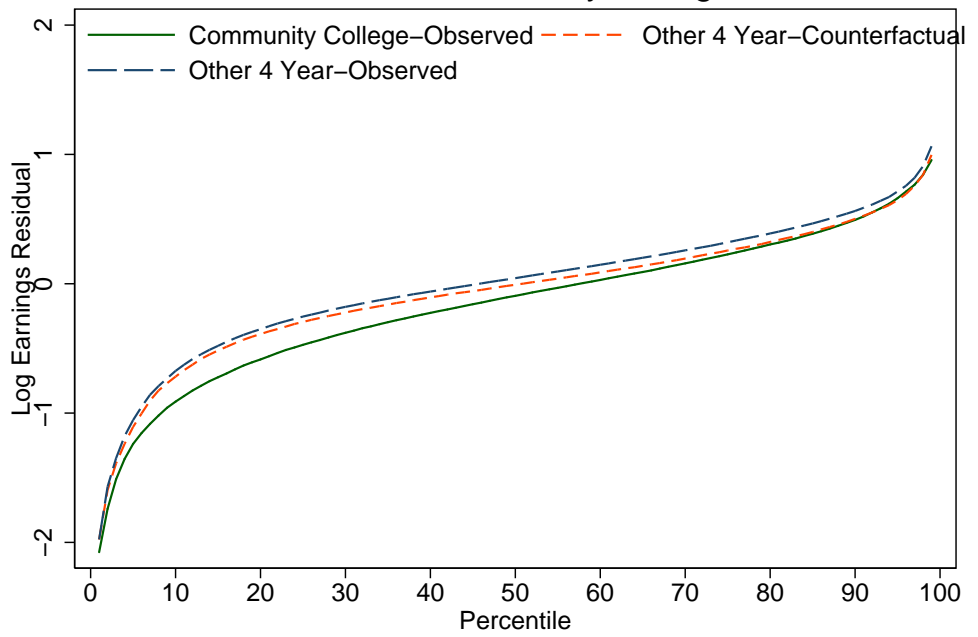

Source: Authors' calculations from the University of Texas at Dallas Education Research Center data and administrative earnings records as described in the text. Each earnings distribution consists of 99 percentile cut-points from the empirical cumulative distribution. The other 4 year counterfactual distribution is the re-weighted other 4 year distribution, where the weights are estimated from equation (8) in the text. 
Figure 4: Quantile Treatment Effects of College Sector Choice on Earnings
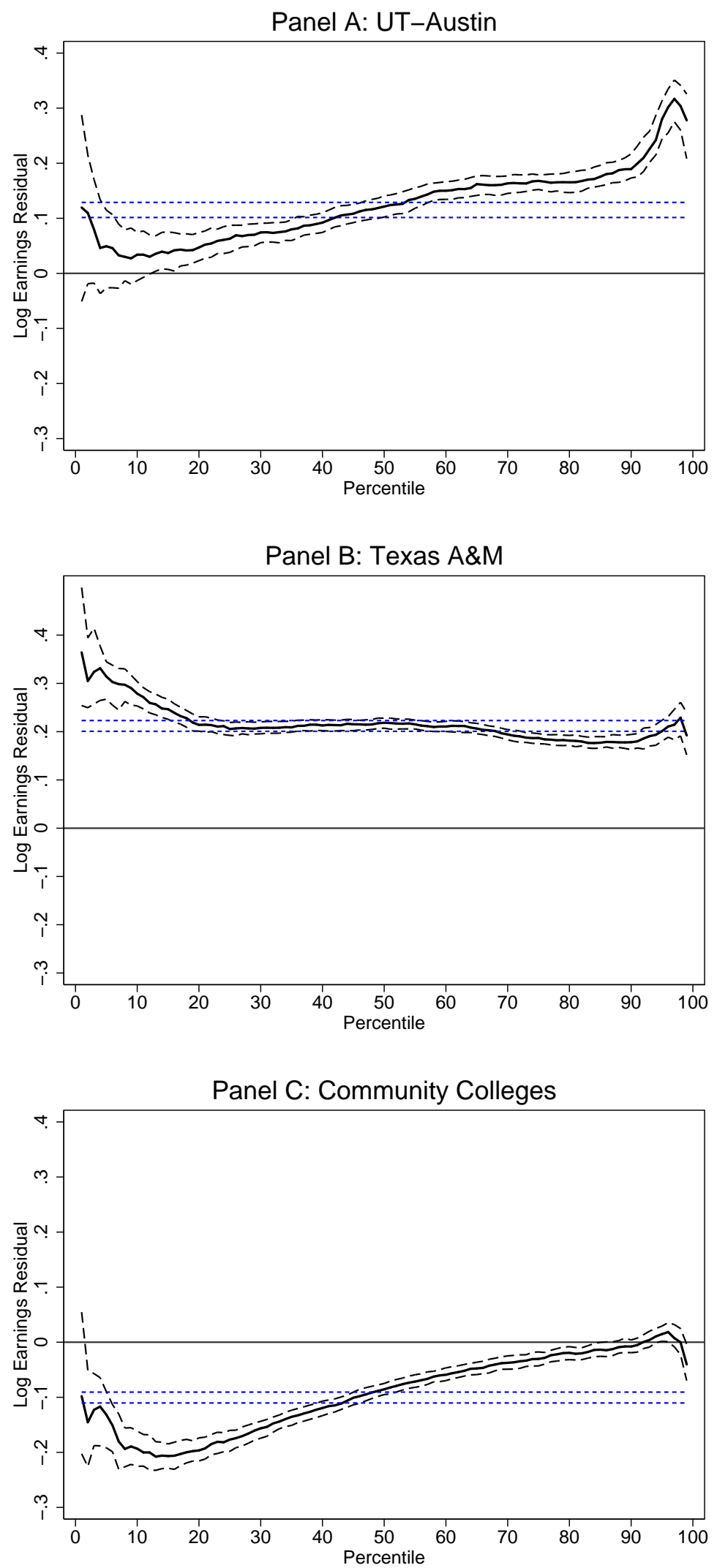

Source: Authors' calculations from the University of Texas at Dallas Education Research Center data and administrative earnings records as described in the text. Each estimated point is the difference between the observed earnings at each percentile for UT-Austin (Panel A), Texas A\&M (Panel B) and community colleges (Panel C) and the associated earnings at that percentile from the counterfactual earnings distribution. The dotted lines show the bounds of the $95 \%$ confidence intervals for each percentile point. The horizontal dashed lines show the $95 \%$ confidence interval of the mean effect from the "All Controls" specification in Table 4. 
Figure 5: Distribution of Majors at UT-Austin and Texas A\&M

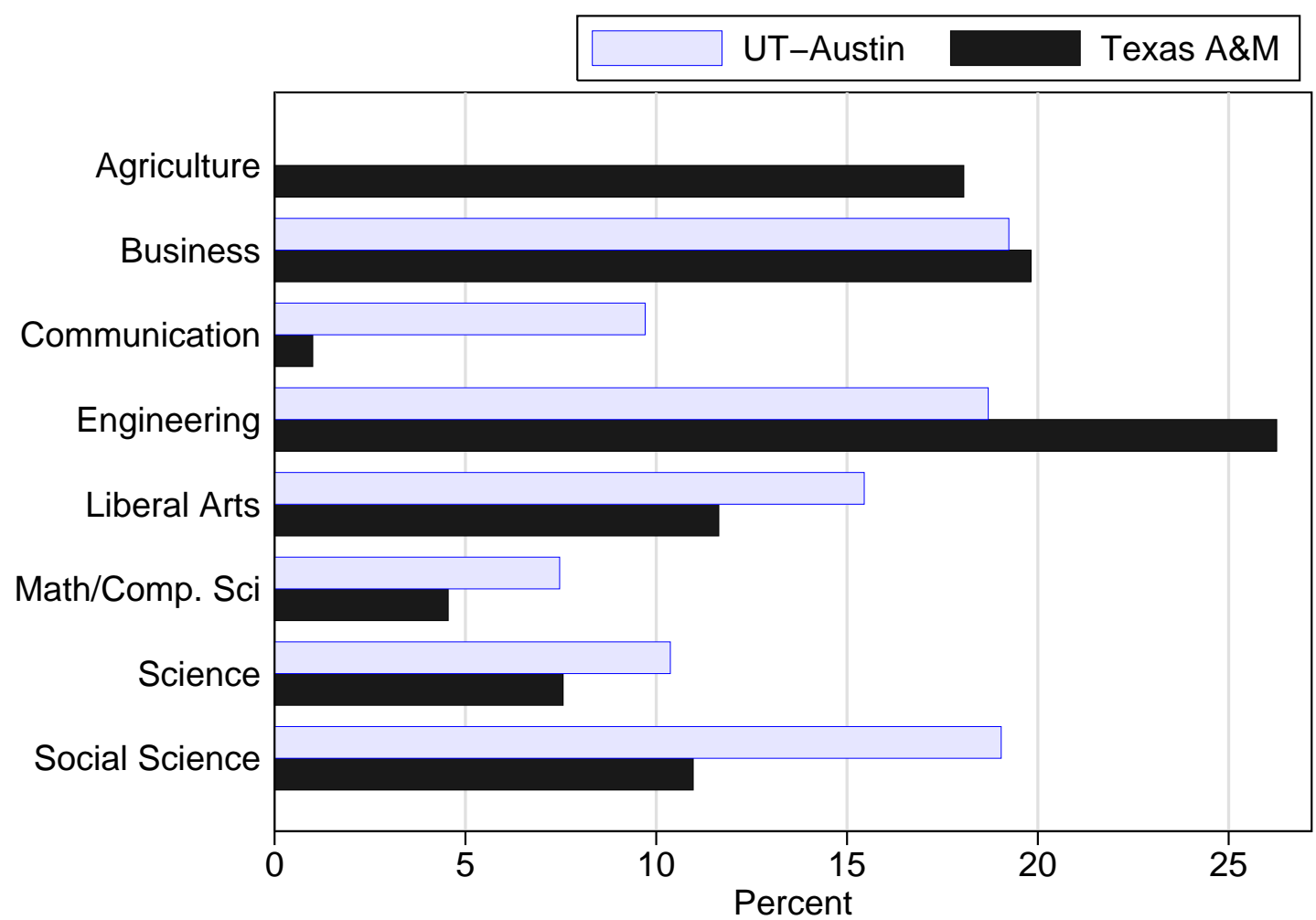

Source: Authors' calculations from the University of Texas at Dallas Education Research Center data. 
Figure 6: Quantile Treatment Effects of Four-year College Sector Choice on Earnings, Including College Major Controls
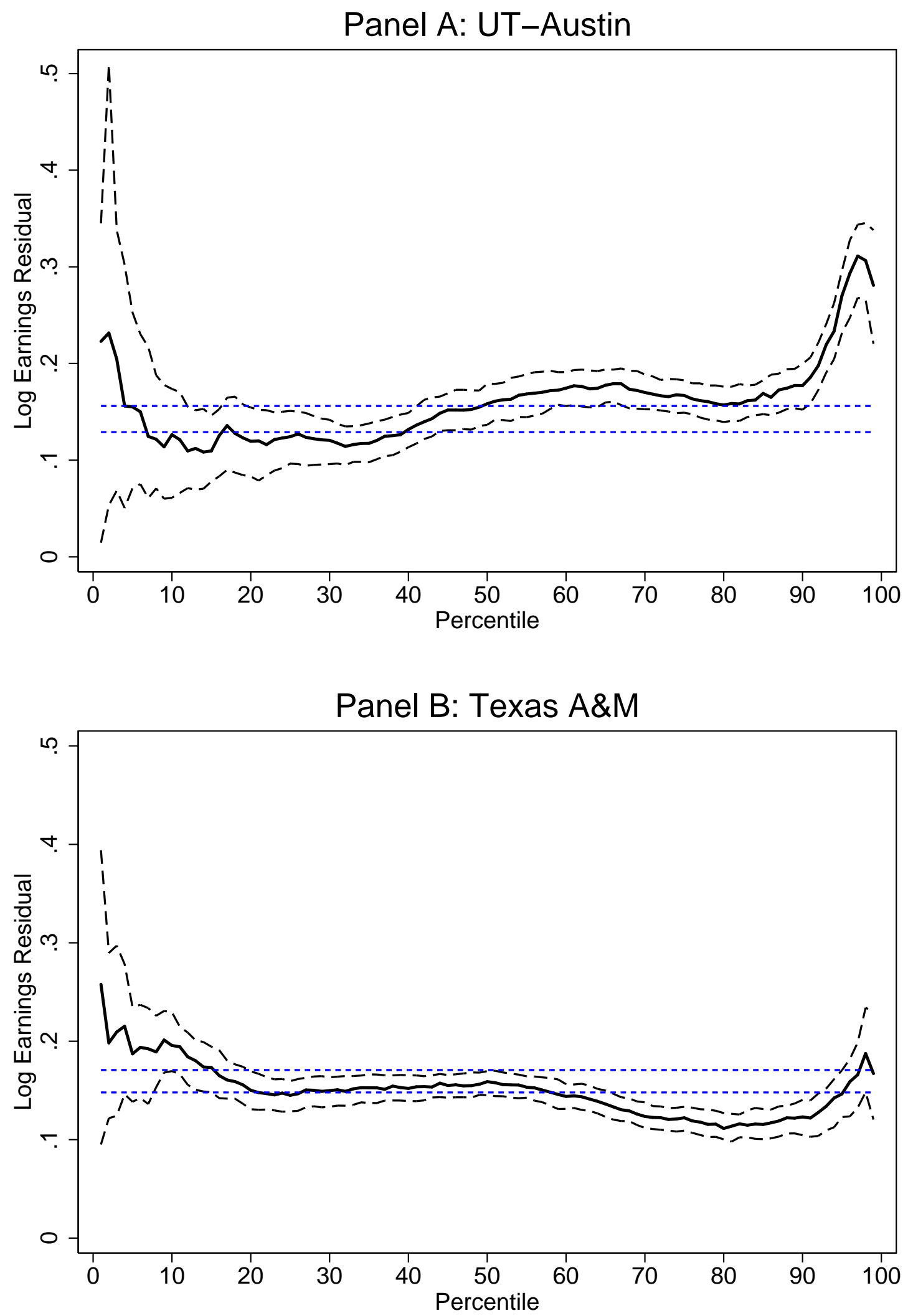

Source: Authors' calculations from the University of Texas at Dallas Education Research Center data and administrative earnings records as described in the text. Each estimated point is the difference between the observed earnings at each percentile for UT-Austin (Panel A) and Texas A\&M (Panel B) and the associated earnings at that percentile from the counterfactual earnings distribution. The dotted lines show the bounds of the $95 \%$ confidence intervals for each percentile point. The horizontal dashed lines show the $95 \%$ confidence interval of the mean effect, calculated using all observables as well as college major controls. 
Figure 7: Quantile Treatment Effects of Graduating from UT-Austin on Earnings by Race
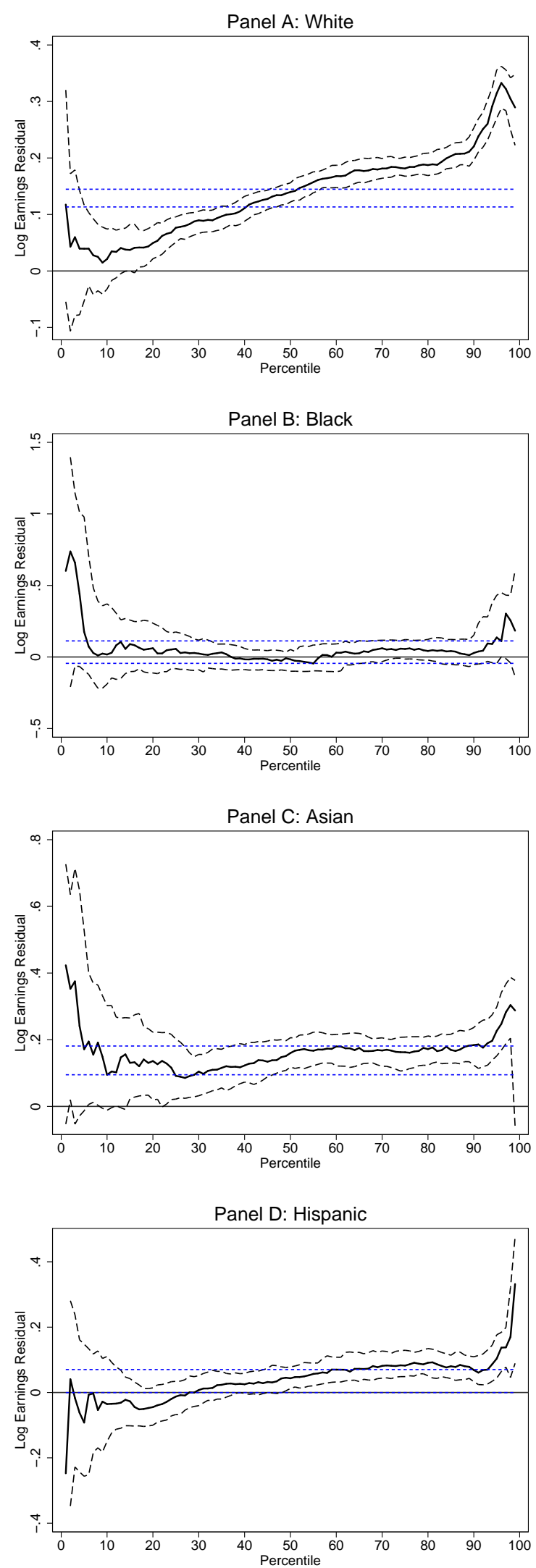

Source: Authors' calculations from the University of Texas at Dallas Education Research Center data and administrative earnings records as described in the text. Each estimated point is the difference between the observed earnings at each percentile for UT-Austin (Panel A), Texas A\&M (Panel B) and community colleges (Panel C) and the associated earnings at that percentile from the counterfactual earnings distribution. The dotted lines show the bounds of the $95 \%$ confidence intervals for each percentile point. The horizontal dashed lines show the $95 \%$ confidence interval of the mean effect from Table 4 . 
Figure 8: Quantile Treatment Effects of Graduating from Texas A\&M - College Station on Earnings by Race
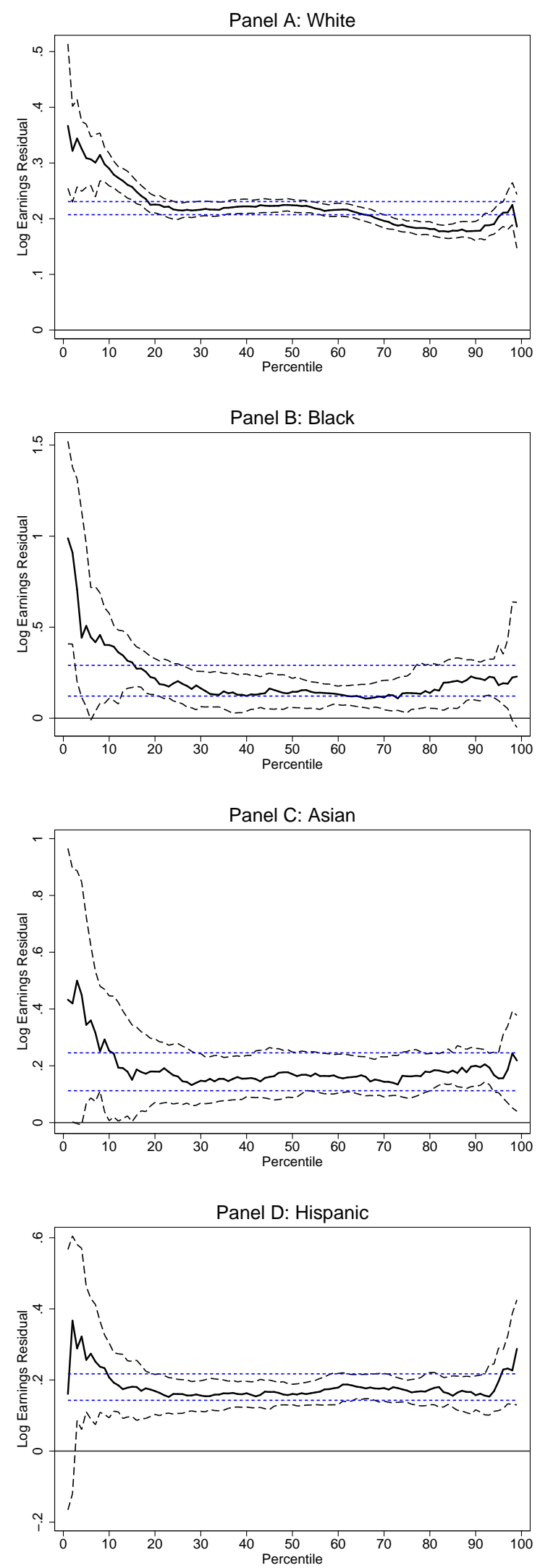

Source: Authors' calculations from the University of Texas at Dallas Education Research Center data and administrative earnings records as described in the text. Each estimated point is the difference between the observed earnings at each percentile for UT-Austin (Panel A), Texas A\&M (Panel B) and community colleges (Panel C) and the associated earnins at that percentile from the counterfactual earnings distribution. The dotted lines show the bounds of the $95 \%$ confidence intervals for each percentile point. The horizontal dashed lines show the $95 \%$ confidence interval of the mean effect from Table 4 . 
Figure 9: Quantile Treatment Effects of Graduating from a Community College on Earnings by Race
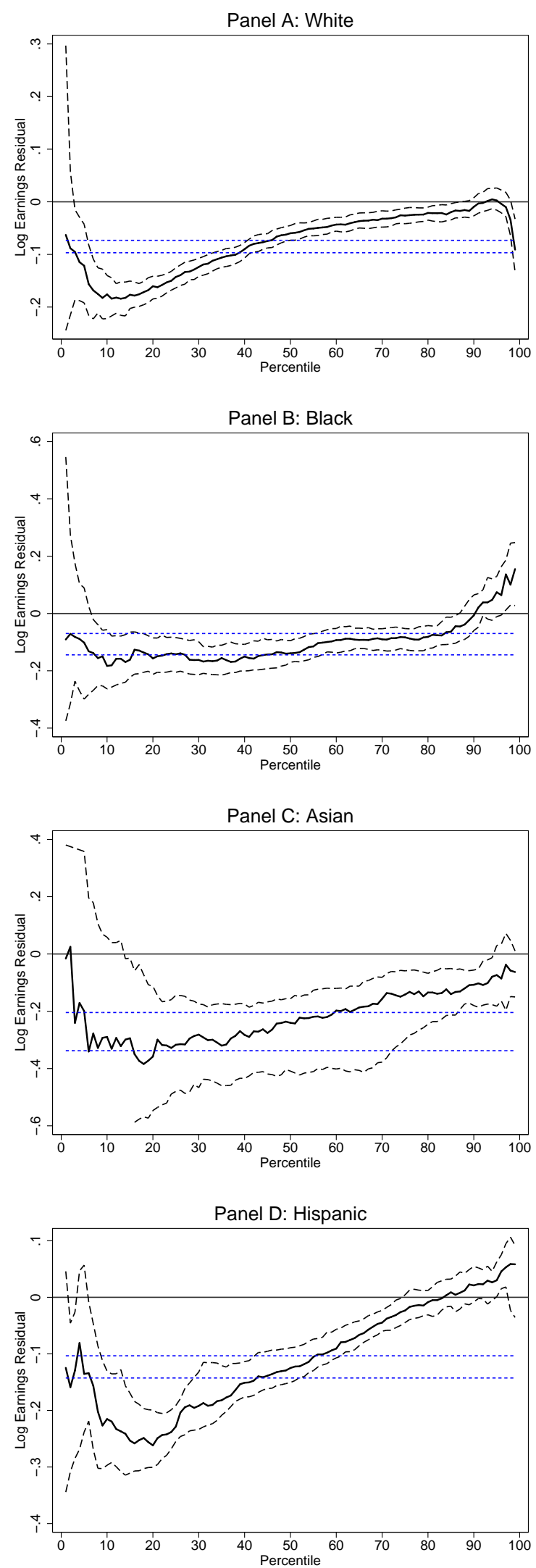

Source: Authors' calculations from the University of Texas at Dallas Education Research Center data and administrative earnings records as described in the text. Each estimated point is the difference between the observed earnings at each percentile for UT-Austin (Panel A), Texas A\&M (Panel B) and community colleges (Panel C) and the associated earnins at that percentile from the counterfactual earnings distribution. The dotted lines show the bounds of the $95 \%$ confidence intervals for each percentile point. The horizontal dashed lines show the $95 \%$ confidence interval of the mean effect from Table 4 . 
Table A-1: Quantile Treatment Effects of College Sector on Earnings by Race/Ethnicity - Graduates

\begin{tabular}{lcccc}
\hline \hline & & \multicolumn{2}{c}{ Panel A: UT-Austin } & \\
\hline \multirow{2}{*}{ Quantile } & White & Black & Asian & Hispanic \\
(iv) $)$
\end{tabular}

\begin{tabular}{|c|c|c|c|c|}
\hline \multicolumn{5}{|c|}{ Panel B: Texas A\&M - College Station } \\
\hline Quantile & $\begin{array}{c}\text { White } \\
\text { (i) }\end{array}$ & $\begin{array}{l}\text { Black } \\
\text { (ii) }\end{array}$ & $\begin{array}{l}\text { Asian } \\
\text { (iii) }\end{array}$ & $\begin{array}{l}\text { Hispanic } \\
\text { (iv) }\end{array}$ \\
\hline \multirow[t]{2}{*}{1} & 0.367 & 0.988 & 0.433 & 0.161 \\
\hline & {$[0.255,0.514]$} & {$[0.408,1.521]$} & {$[-1.674,0.966]$} & {$[-0.166,0.567]$} \\
\hline \multirow[t]{2}{*}{5} & 0.309 & 0.507 & 0.344 & 0.256 \\
\hline & {$[0.256,0.370]$} & {$[0.063,0.957]$} & {$[0.067,0.725]$} & {$[0.110,0.463]$} \\
\hline \multirow[t]{2}{*}{10} & 0.290 & 0.402 & 0.253 & 0.207 \\
\hline & {$[0.259,0.317]$} & {$[0.109,0.577]$} & {$[0.007,0.446]$} & {$[0.094,0.304]$} \\
\hline \multirow[t]{2}{*}{20} & 0.225 & 0.219 & 0.180 & 0.169 \\
\hline & {$[0.210,0.241]$} & {$[0.130,0.327]$} & {$[0.071,0.295]$} & {$[0.103,0.215]$} \\
\hline \multirow[t]{2}{*}{30} & 0.216 & 0.164 & 0.147 & 0.156 \\
\hline & {$[0.205,0.231]$} & {$[0.064,0.257]$} & {$[0.069,0.243]$} & {$[0.112,0.198]$} \\
\hline \multirow[t]{2}{*}{40} & 0.222 & 0.123 & 0.155 & 0.163 \\
\hline & {$[0.210,0.235]$} & {$[0.039,0.243]$} & {$[0.091,0.237]$} & {$[0.124,0.196]$} \\
\hline \multirow[t]{2}{*}{50} & 0.224 & 0.145 & 0.170 & 0.161 \\
\hline & {$[0.212,0.234]$} & {$[0.059,0.219]$} & {$[0.088,0.248]$} & {$[0.131,0.188]$} \\
\hline \multirow[t]{2}{*}{60} & 0.216 & 0.131 & 0.159 & 0.179 \\
\hline & {$[0.204,0.228]$} & {$[0.074,0.176]$} & {$[0.104,0.241]$} & {$[0.131,0.218]$} \\
\hline \multirow[t]{2}{*}{70} & 0.196 & 0.114 & 0.144 & 0.177 \\
\hline & {$[0.183,0.207]$} & {$[0.047,0.208]$} & {$[0.090,0.231]$} & {$[0.141,0.218]$} \\
\hline \multirow[t]{2}{*}{80} & 0.181 & 0.139 & 0.178 & 0.173 \\
\hline & {$[0.171,0.195]$} & {$[0.055,0.296]$} & {$[0.112,0.243]$} & {$[0.131,0.221]$} \\
\hline 90 & 0.178 & 0.220 & 0.200 & 0.157 \\
\hline
\end{tabular}




\begin{tabular}{|c|c|c|c|c|}
\hline \multirow{3}{*}{95} & {$[0.160,0.195]$} & {$[0.099,0.316]$} & {$[0.129,0.262]$} & {$[0.116,0.211]$} \\
\hline & 0.203 & 0.182 & 0.156 & 0.196 \\
\hline & {$[0.179,0.227]$} & {$[0.097,0.402]$} & {$[0.105,0.247]$} & {$[0.114,0.290]$} \\
\hline \multirow[t]{2}{*}{99} & 0.186 & 0.229 & 0.219 & 0.287 \\
\hline & {$[0.147,0.244]$} & {$[-0.051,0.637]$} & {$[0.040,0.377]$} & {$[0.130,0.425]$} \\
\hline \multicolumn{5}{|c|}{ Panel C: Community College } \\
\hline Quantile & $\begin{array}{l}\text { White } \\
\text { (i) }\end{array}$ & $\begin{array}{l}\text { Black } \\
\text { (ii) }\end{array}$ & $\begin{array}{l}\text { Asian } \\
\text { (iii) }\end{array}$ & $\begin{array}{l}\text { Hispanic } \\
\text { (iv) }\end{array}$ \\
\hline \multirow[t]{2}{*}{1} & -0.063 & -0.091 & -0.016 & -0.125 \\
\hline & {$[-0.244,0.297]$} & {$[-0.375,0.546]$} & {$[-1.474,0.380]$} & {$[-0.344,0.046]$} \\
\hline \multirow[t]{2}{*}{5} & -0.121 & -0.102 & -0.199 & -0.135 \\
\hline & {$[-0.192,-0.043]$} & {$[-0.299,0.090]$} & {$[-0.723,0.358]$} & {$[-0.238,0.057]$} \\
\hline \multirow[t]{2}{*}{10} & -0.176 & -0.183 & -0.290 & -0.215 \\
\hline & {$[-0.222,-0.140]$} & {$[-0.263,-0.056]$} & {$[-0.649,0.058]$} & {$[-0.297,-0.131]$} \\
\hline \multirow[t]{2}{*}{20} & -0.160 & -0.157 & -0.358 & -0.262 \\
\hline & {$[-0.185,-0.141]$} & {$[-0.212,-0.085]$} & {$[-0.547,-0.113]$} & {$[-0.301,-0.199]$} \\
\hline \multirow[t]{2}{*}{30} & -0.124 & -0.162 & -0.281 & -0.192 \\
\hline & {$[-0.142,-0.107]$} & {$[-0.213,-0.098]$} & {$[-0.467,-0.175]$} & {$[-0.234,-0.132]$} \\
\hline \multirow[t]{2}{*}{40} & -0.090 & -0.150 & -0.283 & -0.151 \\
\hline & {$[-0.107,-0.077]$} & {$[-0.201,-0.108]$} & {$[-0.434,-0.175]$} & {$[-0.176,-0.114]$} \\
\hline \multirow[t]{2}{*}{50} & -0.060 & -0.139 & -0.240 & -0.125 \\
\hline & {$[-0.073,-0.045]$} & {$[-0.170,-0.095]$} & {$[-0.409,-0.156]$} & {$[-0.151,-0.089]$} \\
\hline \multirow[t]{2}{*}{60} & -0.043 & -0.093 & -0.198 & -0.091 \\
\hline & {$[-0.056,-0.029]$} & {$[-0.138,-0.052]$} & {$[-0.402,-0.120]$} & {$[-0.107,-0.057]$} \\
\hline \multirow[t]{2}{*}{70} & -0.032 & -0.090 & -0.157 & -0.045 \\
\hline & {$[-0.048,-0.017]$} & {$[-0.128,-0.053]$} & {$[-0.377,-0.082]$} & {$[-0.060,-0.023]$} \\
\hline \multirow[t]{2}{*}{80} & -0.021 & -0.082 & -0.134 & -0.009 \\
\hline & {$[-0.035,-0.010]$} & {$[-0.121,-0.042]$} & {$[-0.245,-0.067]$} & {$[-0.031,0.012]$} \\
\hline \multirow[t]{2}{*}{90} & -0.010 & -0.006 & -0.107 & 0.021 \\
\hline & {$[-0.027,0.008]$} & {$[-0.059,0.065]$} & {$[-0.180,-0.056]$} & {$[-0.008,0.055]$} \\
\hline \multirow[t]{2}{*}{95} & 0.002 & 0.074 & -0.074 & 0.030 \\
\hline & {$[-0.016,0.026]$} & {$[-0.011,0.130]$} & {$[-0.182,0.030]$} & {$[0.001,0.063]$} \\
\hline \multirow[t]{2}{*}{99} & -0.091 & 0.155 & -0.063 & 0.058 \\
\hline & {$[-0.133,-0.033]$} & {$[0.028,0.248]$} & {$[-0.150,0.011]$} & {$[-0.036,0.092]$} \\
\hline
\end{tabular}

The table shows the quantile treatment effects for each school type by race/ethnic group with the bounds of the $95 \%$ confidence intervals that are calculated using 250 bootstrap replications in brackets. 
Table A-2: Quantile Treatment Effects of College Sector on Earnings by Race/Ethnicity - Attendees

\begin{tabular}{|c|c|c|c|c|}
\hline \multicolumn{5}{|c|}{ Panel A: UT-Austin } \\
\hline Quantile & $\begin{array}{l}\text { White } \\
\text { (i) }\end{array}$ & $\begin{array}{l}\text { Black } \\
\text { (ii) }\end{array}$ & $\begin{array}{l}\text { Asian } \\
\text { (iii) }\end{array}$ & $\begin{array}{l}\text { Hispanic } \\
\text { (iv) }\end{array}$ \\
\hline \multirow[t]{2}{*}{1} & 0.096 & 0.203 & 0.663 & -0.123 \\
\hline & {$[-0.076,0.327]$} & {$[-0.719,1.140]$} & {$[0.182,1.084]$} & {$[-0.898,0.178]$} \\
\hline \multirow[t]{2}{*}{5} & 0.091 & 0.388 & 0.351 & -0.012 \\
\hline & {$[0.012,0.125]$} & {$[0.084,0.691]$} & {$[0.075,0.606]$} & {$[-0.176,0.189]$} \\
\hline \multirow[t]{2}{*}{10} & 0.097 & 0.254 & 0.135 & 0.111 \\
\hline & {$[0.039,0.148]$} & {$[0.029,0.477]$} & {$[0.033,0.342]$} & {$[0.011,0.211]$} \\
\hline \multirow[t]{2}{*}{20} & 0.110 & 0.241 & 0.130 & 0.063 \\
\hline & {$[0.086,0.142]$} & {$[0.114,0.355]$} & {$[0.054,0.232]$} & {$[0.003,0.144]$} \\
\hline \multirow[t]{2}{*}{30} & 0.125 & 0.129 & 0.112 & 0.077 \\
\hline & {$[0.104,0.150]$} & {$[0.033,0.246]$} & {$[0.060,0.174]$} & {$[0.026,0.137]$} \\
\hline \multirow[t]{2}{*}{40} & 0.131 & 0.108 & 0.132 & 0.080 \\
\hline & {$[0.111,0.160]$} & {$[0.027,0.186]$} & {$[0.079,0.204]$} & {$[0.046,0.121]$} \\
\hline \multirow[t]{2}{*}{50} & 0.166 & 0.041 & 0.153 & 0.082 \\
\hline & {$[0.148,0.190]$} & {$[-0.007,0.124]$} & {$[0.104,0.200]$} & {$[0.038,0.122]$} \\
\hline \multirow[t]{2}{*}{60} & 0.186 & -0.009 & 0.159 & 0.094 \\
\hline & {$[0.170,0.206]$} & {$[-0.054,0.123]$} & {$[0.118,0.199]$} & {$[0.057,0.132]$} \\
\hline \multirow[t]{2}{*}{70} & 0.190 & 0.055 & 0.154 & 0.111 \\
\hline & {$[0.176,0.209]$} & {$[-0.040,0.162]$} & {$[0.115,0.191]$} & {$[0.073,0.139]$} \\
\hline \multirow[t]{2}{*}{80} & 0.193 & 0.077 & 0.141 & 0.109 \\
\hline & {$[0.176,0.214]$} & {$[-0.003,0.133]$} & {$[0.102,0.182]$} & {$[0.076,0.140]$} \\
\hline \multirow[t]{2}{*}{90} & 0.216 & 0.027 & 0.121 & 0.073 \\
\hline & {$[0.191,0.245]$} & {$[-0.078,0.123]$} & {$[0.064,0.194]$} & {$[0.048,0.125]$} \\
\hline \multirow[t]{2}{*}{95} & 0.297 & 0.083 & 0.147 & 0.120 \\
\hline & {$[0.257,0.345]$} & {$[-0.047,0.248]$} & {$[0.078,0.239]$} & {$[0.055,0.183]$} \\
\hline \multirow[t]{2}{*}{99} & 0.290 & 0.313 & -0.055 & 0.235 \\
\hline & {$[0.220,0.331]$} & {$[-0.018,2.301]$} & {$[-0.110,0.185]$} & {$[0.024,0.389]$} \\
\hline \multicolumn{5}{|c|}{ Panel B: Texas A\&M - College Station } \\
\hline Quantile & $\begin{array}{l}\text { White } \\
\text { (i) }\end{array}$ & $\begin{array}{c}\text { Black } \\
\text { (ii) }\end{array}$ & $\begin{array}{c}\text { Asian } \\
\text { (iii) }\end{array}$ & $\begin{array}{l}\text { Hispanic } \\
\text { (iv) }\end{array}$ \\
\hline \multirow[t]{2}{*}{1} & 0.409 & 0.599 & 0.695 & 0.229 \\
\hline & {$[0.309,0.547]$} & {$[-2.349,1.181]$} & {$[0.226,1.116]$} & {$[-0.128,0.575]$} \\
\hline \multirow[t]{2}{*}{5} & 0.355 & 0.256 & 0.381 & 0.287 \\
\hline & {$[0.311,0.414]$} & {$[-0.014,0.611]$} & {$[0.097,0.661]$} & {$[0.113,0.528]$} \\
\hline \multirow[t]{2}{*}{10} & 0.365 & 0.364 & 0.258 & 0.307 \\
\hline & {$[0.332,0.393]$} & {$[0.081,0.594]$} & {$[0.056,0.450]$} & {$[0.211,0.431]$} \\
\hline \multirow[t]{2}{*}{20} & 0.295 & 0.373 & 0.212 & 0.267 \\
\hline & {$[0.278,0.314]$} & {$[0.214,0.485]$} & {$[0.090,0.270]$} & {$[0.191,0.326]$} \\
\hline \multirow[t]{2}{*}{30} & 0.259 & 0.253 & 0.135 & 0.232 \\
\hline & {$[0.244,0.273]$} & {$[0.183,0.362]$} & {$[0.054,0.230]$} & {$[0.184,0.274]$} \\
\hline 40 & 0.250 & 0.214 & 0.173 & 0.199 \\
\hline & {$[0.238,0.261]$} & {$[0.133,0.317]$} & {$[0.070,0.227]$} & {$[0.157,0.233]$} \\
\hline 50 & 0.253 & 0.221 & 0.149 & 0.201 \\
\hline & {$[0.242,0.266]$} & {$[0.121,0.300]$} & {$[0.078,0.198]$} & {$[0.172,0.235]$} \\
\hline 60 & 0.238 & 0.198 & 0.115 & 0.192 \\
\hline & {$[0.227,0.251]$} & {$[0.112,0.260]$} & {$[0.061,0.185]$} & {$[0.154,0.235]$} \\
\hline 70 & 0.211 & 0.156 & 0.115 & 0.193 \\
\hline & {$[0.202,0.223]$} & {$[0.112,0.251]$} & {$[0.054,0.182]$} & {$[0.160,0.230]$} \\
\hline 80 & 0.194 & 0.182 & 0.132 & 0.173 \\
\hline & {$[0.184,0.203]$} & {$[0.086,0.299]$} & {$[0.055,0.196]$} & {$[0.140,0.211]$} \\
\hline 90 & 0.180 & 0.232 & 0.129 & 0.162 \\
\hline
\end{tabular}




\begin{tabular}{|c|c|c|c|c|}
\hline \multirow{3}{*}{95} & {$[0.164,0.195]$} & {$[0.098,0.353]$} & {$[0.057,0.191]$} & {$[0.121,0.192]$} \\
\hline & 0.203 & 0.242 & 0.074 & 0.179 \\
\hline & {$[0.176,0.227]$} & {$[0.086,0.357]$} & {$[-0.014,0.201]$} & {$[0.101,0.240]$} \\
\hline \multirow[t]{2}{*}{99} & 0.179 & 0.205 & -0.082 & 0.224 \\
\hline & {$[0.143,0.213]$} & {$[-0.192,0.655]$} & {$[-0.269,0.182]$} & {$[0.055,0.367]$} \\
\hline \multicolumn{5}{|c|}{ Panel C: Community College } \\
\hline Quantile & $\begin{array}{l}\text { White } \\
\text { (i) }\end{array}$ & $\begin{array}{l}\text { Black } \\
\text { (ii) }\end{array}$ & $\begin{array}{l}\text { Asian } \\
\text { (iii) }\end{array}$ & $\begin{array}{l}\text { Hispanic } \\
\text { (iv) }\end{array}$ \\
\hline \multirow[t]{2}{*}{1} & -0.165 & 0.025 & -0.143 & -0.118 \\
\hline & {$[-0.249,-0.052]$} & {$[-0.230,0.232]$} & {$[-0.552,0.254]$} & {$[-0.295,0.148]$} \\
\hline \multirow[t]{2}{*}{5} & -0.167 & -0.108 & -0.068 & -0.024 \\
\hline & {$[-0.199,-0.103]$} & {$[-0.243,0.041]$} & {$[-0.317,0.163]$} & {$[-0.093,0.036]$} \\
\hline \multirow[t]{2}{*}{10} & -0.192 & -0.074 & -0.173 & -0.021 \\
\hline & {$[-0.208,-0.118]$} & {$[-0.152,0.014]$} & {$[-0.297,-0.019]$} & {$[-0.078,0.023]$} \\
\hline \multirow[t]{2}{*}{20} & -0.174 & -0.088 & -0.159 & -0.079 \\
\hline & {$[-0.193,-0.154]$} & {$[-0.013,-0.022]$} & {$[-0.285,0.074]$} & {$[-0.110,-0.042]$} \\
\hline \multirow[t]{2}{*}{30} & -0.147 & -0.083 & -0.208 & -0.107 \\
\hline & {$[-0.163,-0.136]$} & {$[-0.118,-0.041]$} & {$[-0.290,-0.059]$} & {$[-0.134,-0.078]$} \\
\hline \multirow[t]{2}{*}{40} & -0.131 & -0.089 & -0.190 & -0.100 \\
\hline & {$[-0.144,-0.118]$} & {$[-0.128,-0.062]$} & {$[-0.264,-0.117]$} & {$[-0.122,-0.076]$} \\
\hline \multirow[t]{2}{*}{50} & -0.102 & -0.100 & -0.208 & -0.100 \\
\hline & {$[-0.113,-0.092]$} & {$[-0.133,-0.075]$} & {$[-0.254,-0.141]$} & {$[-0.124,-0.077]$} \\
\hline \multirow[t]{2}{*}{60} & -0.080 & -0.095 & -0.199 & -0.110 \\
\hline & {$[-0.091,-0.069]$} & {$[-0.119,-0.073]$} & {$[-0.240,-0.140]$} & {$[-0.128,-0.089]$} \\
\hline \multirow[t]{2}{*}{70} & -0.069 & -0.093 & -0.173 & -0.099 \\
\hline & {$[-0.081,-0.060]$} & {$[-0.116,-0.070]$} & {$[-0.227,-0.117]$} & {$[-0.113,-0.081]$} \\
\hline \multirow[t]{2}{*}{80} & -0.055 & -0.098 & -0.181 & -0.080 \\
\hline & {$[-0.069,-0.046]$} & {$[-0.125,-0.072]$} & {$[-0.235,-0.128]$} & {$[-0.097,-0.062]$} \\
\hline \multirow[t]{2}{*}{90} & -0.042 & -0.075 & -0.135 & -0.069 \\
\hline & {$[-0.055,-0.027]$} & {$[-0.092,-0.057]$} & {$[-0.209,-0.087]$} & {$[-0.100,-0.044]$} \\
\hline \multirow[t]{2}{*}{95} & -0.026 & -0.037 & -0.143 & -0.061 \\
\hline & {$[-0.041,-0.009]$} & {$[-0.066,-0.005]$} & {$[-0.205,-0.035]$} & {$[-0.085,-0.031]$} \\
\hline \multirow[t]{2}{*}{99} & -0.053 & 0.013 & -0.218 & -0.057 \\
\hline & {$[-0.092,-0.008]$} & {$[-0.069,0.086]$} & {$[-0.416,0.102]$} & {$[-0.083,-0.018]$} \\
\hline
\end{tabular}

The table shows the quantile treatment effects for each school type by race/ethnic group with the bounds of the $95 \%$ confidence intervals that are calculated using 250 bootstrap replications in brackets. 